\title{
Human DNA Polymerase a Uses a Combination of Positive and Negative Selectivity to Polymerize Purine dNTPs with High Fidelity ${ }^{\dagger}$
}

\author{
Jeff Beckman, \\ Department of Chemistry and Biochemistry, University of Colorado, Boulder, CO 80309-0215 \\ Kristi Kincaid, \\ Department of Chemistry and Biochemistry, University of Colorado, Boulder, CO 80309-0215 \\ Michal Hocek, \\ Centre for New Antivirals and Antineoplastics, Institute of Organic Chemistry and Biochemistry, \\ Academy of Sciences of the Czech Republic, CZ-16610 Prague 6, Czech Republic
}

Thomas Spratt, Department of Biochemistry and Molecular Biology, Penn State College of Medicine, 500 University Drive, Hershey PA 17033

Joachim Engels, Institut für Organische Chemie, Johann Wolfgang Goethe Universität, Marie Curie Strasse 11, $D$-60439 Frankfurt am Main, Germany

Richard Cosstick, and Department of Chemistry, University of Liverpool, Crown Street, Liverpool L69 3BX

Robert D. Kuchta* Department of Chemistry and Biochemistry, University of Colorado, Boulder, CO 80309-0215

\section{Abstract}

DNA polymerases accurately replicate DNA by incorporating mostly correct dNTPs opposite any given template base. We have identified the chemical features of purine dNTPs that human pol $\alpha$ uses to discriminate between right and wrong dNTPs. Removing N-3 from guanine and adenine, two high fidelity bases, significantly lowers fidelity. Analogously, adding the equivalent of N-3 to lowfidelity benzimidazole-derived bases (i.e., bases that pol $\alpha$ rapidly incorporates opposite all 4 natural bases) and to generate 1-deazapurines significantly increases the ability of pol $\alpha$ to identify the resulting 1-deazapurines as wrong. Adding the equivalent of the purine $\mathrm{N}-1$ to benzimidazole or to 1-deazapurines significantly decreases the rate at which pol $\alpha$ polymerizes the resulting bases opposite A, C, and G, while simultaneously enhancing polymerization opposite T. Conversely, adding the equivalent of adenine's $\mathrm{C}-6$ exocyclic amine (N-6) to 1- and 3-deazapurines also enhances polymerization opposite $\mathrm{T}$, but does not significantly decrease polymerization opposite $\mathrm{A}, \mathrm{C}$, and $\mathrm{G}$. Importantly, if the newly inserted bases lack $\mathrm{N}-1$ and $\mathrm{N}-6$, pol $\alpha$ does not efficiently polymerize the next correct dNTP, whereas if it lacks N-3 one additional nucleotide is added and then chain termination ensues. These data indicate that pol $\alpha$ uses two orthogonal screens to maximize its fidelity. During dNTP polymerization, it uses a combination of negative (N-1 and N-3) and positive ( $\mathrm{N}-1$ and

\footnotetext{
${ }^{\dagger}$ This work was supported by grants to RDK from the NIH (GM54194 and TW007372-01) and the Army Research Office (W911NF-05-1-0172), to MH from the Ministry of Education of the Czech Republic (Centre of Biomolecules and Complex Molecular Systems, LC 512), and to JE from the Deutsche Forschungsgemeinschaft (SFB 579).

*To whom correspondence should be addressed. Email: kuchta@ colorado.edu. Phone: 303-492-7027. FAX: 303-492-5894.
} 
$\mathrm{N}-6$ ) selectivity to differentiate between right and wrong dNTPs, while the shape of the base-pair is essentially irrelevant. Then, to determine whether or not to add further dNTPs onto the just added nucleotide, pol $\alpha$ appears to monitor the shape of the base-pair at the primer 3 '-terminus. The biological implications of these results are discussed.

\section{Introduction}

A hallmark feature of cells is their ability to accurately replicate DNA. This is thought to result from a three-stage process. First, replicative DNA polymerases rarely incorporate the wrong dNTP. Second, the polymerase proofreads the newly incorporated nucleotide. If the just added nucleotide is correct, polymerization continues at a rapid rate. However, if the nucleotide is incorrect, the rate of addition of the next correct dNTP becomes very slow, allowing the polymerase to either excise the error itself or dissociate and allow a separate exonuclease to perform the task. Finally, if the polymerase incorporates an incorrect dNTP and follows by polymerizing additional dNTPs, post-replicative repair enzymes can remove the incorrect nucleotide and fill the resulting gap. Overall, this results in an error frequency of ca. $10^{-9}$ errors per nucleotide inserted (1).

Replicative DNA polymerases, e.g. DNA polymerase $\alpha$ ( $\operatorname{pol}^{1}$ ), exhibit error frequencies of $10^{-3}$ to $10^{-6}$ errors per nucleotide inserted $(2,3)$. Over the last few decades, multiple theories have been proposed to account for the ability of these polymerases to accurately differentiate between right and wrong dNTPs. Originally, Watson and Crick proposed that replication fidelity is due to the self-complementarity of the bases via the two hydrogen bonds between A and $T$ and the three between $G$ and $C(4,5)$. Although recent studies have shown that two low fidelity RNA polymerases, human and herpes DNA primase, most likely incorporate correct NTPs based on these hydrogen bonds $(6,7)$, many DNA polymerases clearly do not use this mechanism. In a series of pioneering studies, Kool and coworkers showed that some DNA polymerases (ex. Klenow fragment) will generate a base pair between analogues containing the bases 2,4-difluorotoluene, a thymine isostere, and 4-methylbenzimidazole, an adenine isostere. These studies clearly indicated that some polymerases do not require formation of Watson-Crick hydrogen bonds for rapid dNTP polymerization, and suggest that the shape of the incipient base pair may help some polymerases discriminate right and wrong dNTPs (8$10)$.

However, recent studies using human pol $\alpha$, a B-family polymerase, showed that this enzyme does not require either formation of hydrogen bonds or a correctly shaped incipient base pair to rapidly polymerize a dNTP $(11,12)$. Pol $\alpha$ polymerizes dNTP analogues containing bases such as benzimidazole, 4-methoxybenzimidazole and 5,6-dinitrobenzimidazole opposite all four natural template bases with remarkable efficiency, incorporating them at rates approaching those for a correct, natural dNTP, and orders of magnitude faster than an incorrect, natural $\mathrm{dNTP}\left(\mathrm{V}_{\mathrm{MAX}} / \mathrm{K}_{\mathrm{M}}\right)$. While we do not know the shape of the base-pairs formed between these

\footnotetext{
${ }^{1}$ Abbreviations used: A, adenine; 4AB, 4-aminobenzimidazole; B, benzimidazole; 1DA, 1-deazaadenine; Q, 1-deaza-6-methylpurine; 1DP, 1-deazapurine; 3DP, 3-deazapurine; Z, 4-methylbenzimidazole; 6MP, 6-methylpurine; $\mathrm{P}$, purine; 4F3 $\mathrm{B}$, 4trifluoromethylbenzimidazole; $6 \mathrm{~F}_{3} \mathrm{P}$, 6-trifluoromethylpurine; d1DATP, 9- $\beta$-D-2'-deoxyribofuranosyl-(1-deazaadenine)-5'triphosphate; d1DPTP, 9- $\beta$-D-2'-deoxyribofuranosyl-(1-deazapurine)-5'-triphosphate; d3DATP, 9- $\beta$-D-2'-deoxyribofuranosyl-(3deazaadenine)-5'-triphosphate; d3DGTP, 9- $\beta$-D-2'-deoxyribofuranosyl-(3-deazaguanine)-5'-triphosphate; d3DPTP, 9- $\beta$-D-2'deoxyribofuranosyl-(3-deazapurine)-5'-triphosphate; d4ABTP, 1- $\beta$-D-2'-deoxyribofuranosyl-(4-aminobenzimidazole)-5'-triphosphate; $\mathrm{d}_{4} \mathrm{~F}_{3} \mathrm{BTP}, 1-\beta-\mathrm{D}-2^{2}$-deoxyribofuranosyl-(4-trifluoromethylbenzimidazole)-5'-triphosphate; d6 $\mathrm{F}_{3} \mathrm{PTP}, 9-\beta-\mathrm{D}-2^{\prime}$-deoxyribofuranosyl-(6trifluoromethylpurine)-5'-triphosphate; d6MPTP, 9- $\beta$-D-2'-deoxyribofuranosyl-(6-methylpurine)-5'-triphosphate; dBTP, 1- $\beta$-D-2'deoxyribofuranosyl-(benzimidazole)-5'-triphosphate; dNTP, natural 2'-deoxy-5'-triphosphate; dPTP, 9- $\beta$-D-2'-deoxyribofuranosyl(purine)-5'-triphosphate; dQTP, 9- $\beta$-D-2'-deoxyribofuranosyl-(1-deaza-6-methylpurine)-5'-triphosphate; dZTP, 1- $\beta$-D-2'deoxyribofuranosyl-(4-methylbenzimidazole)-5'-triphosphate; ESI, electrospray ionization; MALDI, matrix assisted laser desorption/ ionization; NOE, nuclear overhauser effect; Pol $\alpha$, DNA polymerase $\alpha$; THAP, 2',4',6'-trihydroxyacetophenone; and Tris-HCl, tris (hydroxymethyl)aminomethane-hydrochloric acid.
} 
analogues and, for example, adenine or guanine, it clearly must be quite different than a canonical base-pair. Thus, a correctly shaped base-pair is not essential for dNTP polymerization by pol $\alpha$. These studies also indicated that the rapid polymerization of these unnatural, low fidelity bases did not result from their relatively high hydrophobicity (11).

Importantly, after pol $\alpha$ incorporates these low fidelity nucleotides it does not efficiently incorporate the next correct dNTP. These data suggest that pol $\alpha$ uses very different mechanisms to choose whether or not to polymerize a dNTP versus when to rapidly add further dNTPs onto a newly polymerized nucleotide, and has led to the idea that pol $\alpha$ uses two orthogonal screens to ensure fidelity. The first screen occurs during dNTP polymerization where pol $\alpha$ uses one set of parameters to decide whether or not to polymerize the dNTP. The second screen occurs during addition of the next correct dNTP onto a primer terminus, and pol $\alpha$ now uses a different set of parameters.

To better understand how pol $\alpha$ discriminates between right and wrong dNTPs, we posed two questions. What chemical features have to be added to an unnatural, low fidelity base (e.g. benzimidazole or 4-methylbenzimidazole) to convert it into a high fidelity base (e.g. adenine), and what chemical features have to be removed from a high fidelity base to convert it into a low fidelity base? Pol $\alpha$ uses N-1 and N-3 of a purine to specifically prevent misincorporation of a purine dNTP, whereas N-1 and adenine's exocyclic amine at C-6 specifically enhance the correct incorporation of the dNTP. In contrast, the shape of the base pair at the primer 3'terminus appears to primarily dictate the rate at which pol $\alpha$ polymerizes additional dNTPs.

\section{Experimental Procedures}

\section{Materials}

All reagents were of the highest quality commercially available. Unlabeled dNTPs were purchased from Sigma and radiolabeled dNTPs from New England Nuclear. Synthetic oligonucleotides were purchased from Oligos, Etc. or BioSearch, and their concentrations determined spectrally. Human pol $\alpha$ (4-subunit complex) was expressed and purified as previously described (13). 9-(2-Deoxy- $\beta$-D-erythro-pentofuranosyl)-purine was purchased from Berry and Associates (Ann Arbor, MI). 9-(2-Deoxy- $\beta$-D-erythro-pentofuranosyl)-1deazapurine was synthesized as previously described (14). 9-(2-Deoxy- $\beta$-D-erythropentofuranosyl)-6-chloro-3-deazapurine (Berry and Associates) was hydrogenated to 9-(2deoxy- $\beta$-D-erythro-pentofuranosyl)-3-deazapurine as previously described (15). 1- $\beta$-D-2'Deoxyribofuranosyl-(4-Trifluoromethylbenzimidazole)-5'-triphosphate $\left(\mathrm{d}_{4} \mathrm{~F}_{3} \mathrm{BTP}\right), 1-\beta$ D-2'-deoxyribofuranosyl-(4-methylbenzimidazole)-5'-triphosphate (dZTP), 9- $\beta$-D-2'deoxyribofuranosyl-(1-deaza-6-methylpurine)-5'-triphosphate (dQTP), 9- $\beta$-D-2'deoxyribofuranosyl-(3-deazaadenine)-5'-triphosphate (d3DATP), and 9- $\beta-\mathrm{D}-2^{\prime}$ deoxyribofuranosyl-(3-deazaguanine)-5'-triphosphate (d3DGTP) were synthesized as previously described $(9,11,16-19)$. Triphosphorylation of 9-(2-deoxy- $\beta$-D-erythropentofuranosyl)-1-deazaadenine to 9- $\beta$-D-2'-deoxyribofuranosyl-(1-deazaadenine)-5'triphosphate (d1DATP) was performed by Sierra Bioresearch (Tuscon, AZ).

\section{Chemical Methods}

Unless otherwise noted, materials from commercial sources were used without further purification. Chromatographic separations were performed on grade 62, 60-200 mesh (Aldrich). Thin layer chromatography was performed on aluminum silica gel plates (Silica Gel $60 \mathrm{~F}_{254}$, EMD Chemicals Inc.) ${ }^{1} \mathrm{H}$ NMR was performed on either Inova $400 \mathrm{MHz}$ or Varian $500 \mathrm{MHz}$ instruments and internally referenced to trace impurity $\left(\mathrm{H}_{2} \mathrm{O}\right) .{ }^{31} \mathrm{P}$ NMR was performed on the Inova $400 \mathrm{MHz}$ instrument and referenced using $85 \%$ phosphoric acid in a 
capillary tube inserted into the sample. All chemical shifts are reported in ppm $(\delta)$ unless otherwise noted.

\section{Synthesis of Nucleosides}

Synthesis was achieved by glycosylating a purine (analogue) with 1-( $\alpha$ )-chloro-3,5-di- $O$-( $p$ toluoyl)-2-deoxy-D-ribose (Berry and Associates) using the procedure of Kazimierczuk and colleagues (20). Briefly, the purine/purine analogue was added to enough dry $\mathrm{MeCN}$ to fully dissolve it (Approximately $20 \mathrm{mM}$ solution is typical). $\mathrm{NaH}$ (60\% in oil, 1 eq.) was then added and the mixture allowed to equilibrate at room temperature for 30 minutes. This mixture was cooled on ice and the 1-( $\alpha$ )-chloro-3,5-di- $O$-( $p$-toluoyl)-2-deoxy-D-ribose (1 eq) added. After approximately three hours on ice, the slurry was filtered, dried under vacuum, then silica purified using 70:30 ethyl acetate (EtOAc):Hexanes for benzimidazole nucleosides and 95:5 methylene chloride $\left(\mathrm{CH}_{2} \mathrm{Cl}_{2}\right)$ :MeOH for 1-deazapurine nucleosides. Yields were generally between $40 \%$ and $70 \%$, depending on the percentage of $\beta$ to $\alpha$ anomers and regioisomers that formed during coupling. Protected nucleosides were de-protected by dissolving them first in $\mathrm{MeOH}$ followed by addition of sodium methoxide $(\mathrm{NaOMe})$ (Approximately $10 \mathrm{mM}$ starting material in $\mathrm{MeOH}$ was typical; 2 eq of $\mathrm{NaOMe}$ ). After 2 to 3 hours, the reaction was quenched using excess ammonium chloride $\left(\mathrm{NH}_{4} \mathrm{Cl}\right)$, filtered, and dried under vacuum. A small amount of $\mathrm{ddH}_{2} \mathrm{O}(10 \mathrm{~mL})$ was added to dissolve the solids, and the product extracted twice into EtOAc $(2 \times 100 \mathrm{~mL})$. The organic layer was dried using magnesium sulfate $\left(\mathrm{MgSO}_{4}\right)$, filtered, and the nucleoside purified using silica flash chromatography $\left(9: 1 \mathrm{CH}_{2} \mathrm{Cl}_{2}: \mathrm{MeOH}\right)$ followed by

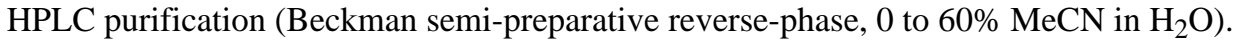
Typically yields were between $80 \%$ and $90 \%$. Using NOE (GOESY) NMR, benzimidazole bases were assigned as the correct regioisomer by observing the interaction between $\mathrm{C} 7$ of the base and anomeric $\mathrm{H}-1^{\prime}$ of the 2'-deoxyribose. For 1-deazapurines, the lack of interaction between the anomeric proton and the base was observed.

\section{Synthesis of 9-(2-Deoxy- $\beta$-D-erythro-pentofuranosyl)-1-deazaadenine}

1-Deazaadenine $(130 \mathrm{mg}(1 \mathrm{mmol})$, synthesized as previously described $(21,22))$ was protected at its exocyclic amine to form the acetamide by dissolving it into $20 \mathrm{~mL}$ of a pyridine:acetic anhydride solution (3:1) and heating to $70^{\circ} \mathrm{C}$ for 6 hours. After cooling to room temperature, it was dried under vacuum, triturated into $150 \mathrm{~mL}$ EtOAc, filtered, then vacuum dried. The 6acetamide-1-deazaadenine was purified as a yellow solid in $70 \%$ yield using silica flash chromatography (9:1 $\left.\mathrm{CH}_{2} \mathrm{Cl}_{2}: \mathrm{MeOH}\right) .{ }^{1} \mathrm{H}$ NMR $\left(400 \mathrm{MHz}, d_{4}\right.$-methanol): $\delta 8.75(1 \mathrm{H}, \mathrm{s}$, $\left.\mathrm{C}_{2} \mathrm{H}\right) ; 8.32\left(1 \mathrm{H}, \mathrm{d}, J_{\text {gem }}=6.0 \mathrm{~Hz}, \mathrm{ArH}\right) ; 8.21\left(1 \mathrm{H}, \mathrm{d}, J_{\text {gem }}=6.0 \mathrm{~Hz}, \mathrm{ArH}\right) ; 2.26\left(3 \mathrm{H}, \mathrm{s}, \mathrm{CH}_{3}\right)$. 6-Acetamide-1-deazaadenine $(90 \mathrm{mg}, 500 \mu \mathrm{mol})$ was dissolved into $20 \mathrm{~mL}$ of dry MeCN $(25$ $\mathrm{mM}$ solution) and the protected nucleoside was generated in 50\% yield using the procedure described earlier. The protected nucleoside $(50 \mathrm{mg}, 95 \mu \mathrm{mol})$ was dissolved in $15 \mathrm{~mL}$ of $\mathrm{MeOH}$ saturated with ammonia (saturated at $0^{\circ} \mathrm{C} ; 6 \mathrm{mM}$ solution), allowed to de-protect overnight at room temperature, dried under vacuum, then purified by silica flash chromatography (9:1 $\mathrm{CH}_{2} \mathrm{Cl}_{2}: \mathrm{MeOH}$ ) to produce 9-(2-Deoxy- $\beta$-D-erythro-pentofuranosyl)-6-acetamide-1deazapurine in $90 \%$ yield. ${ }^{1} \mathrm{H}$ NMR $\left(500 \mathrm{MHz}, d_{4}\right.$-methanol): $\delta 8.45\left(1 \mathrm{H}, \mathrm{s}, \mathrm{C}_{2} \mathrm{H}\right) ; 8.19(1 \mathrm{H}$, d, $\left.J_{\text {gem }}=7.0 \mathrm{~Hz}, \mathrm{ArH}\right) ; 8.14\left(1 \mathrm{H}, \mathrm{d}, J_{\text {gem }}=7.0 \mathrm{~Hz}, \mathrm{ArH}\right) ; 6.50\left(1 \mathrm{H}, \mathrm{dd}, J_{1^{\prime}, 2^{\prime}}=8.0,10.5 \mathrm{~Hz}\right.$, H-1'); 4.57 (1H, m, H-3'); 4.06 (1H, m, H-4'); 3.70-3.84 (2H, m, H-5'); 2.85 (1H, m, H-2'b); $2.37\left(1 \mathrm{H}, \mathrm{m}, \mathrm{H}-2\right.$ 'a); $2.24\left(3 \mathrm{H}, \mathrm{s}, \mathrm{CH}_{3}\right)$. Conversion to 9-(2-deoxy- $\beta$-D-erythro-

pentofuranosyl)-1-deazaadenine in $90 \%$ yield was obtained by dissolving $40 \mathrm{mg}$ of 9-(2-deoxy$\beta$-D-erythro-pentofuranosyl)-6-acetamide-1-deazapurine in $\mathrm{MeOH}$ (10 mM solution), adding excess $\mathrm{NaOMe}$ (Approximately 3 eq), and refluxing for six hours followed by addition of excess $\mathrm{NH}_{4} \mathrm{Cl}$ and letting it stir one additional hour. After filtering and vacuum drying the product was purified by flash chromatography $\left(92: 8 \mathrm{CH}_{2} \mathrm{Cl}_{2}: \mathrm{MeOH}\right) .{ }^{1} \mathrm{H} \mathrm{NMR}(400 \mathrm{MHz}$, $d_{4}$-methanol): $\delta 8.22\left(1 \mathrm{H}, \mathrm{s}, \mathrm{C}_{2} \mathrm{H}\right) ; 7.81\left(1 \mathrm{H}, \mathrm{d}, J_{\text {gem }}=6.0 \mathrm{~Hz}, \mathrm{ArH}\right) ; 6.46\left(1 \mathrm{H}, \mathrm{d}, J_{\text {gem }}=6.0\right.$ $\left.\mathrm{Hz}, \mathrm{ArH}) ; 6.40\left(1 \mathrm{H}, \mathrm{dd}, J_{l^{\prime}, 2^{\prime}}=6.0,8.8 \mathrm{~Hz}, \mathrm{H}^{\prime}\right)^{\prime}\right) ; 4.54\left(1 \mathrm{H}, \mathrm{m}, \mathrm{H}-3^{\prime}\right) ; 4.05\left(1 \mathrm{H}, \mathrm{m}, \mathrm{H}-4^{\prime}\right)$; 
3.69-3.84 (2H, m, H-5'); 2.84 (1H, m, H-2'b); 2.33 (1H, m, H-2'a). MS (ESI+): 251.1134 ([M $+\mathrm{H}]^{+}$calc. 251.1138).

\section{Synthesis of 9-(2-Deoxy- $\beta$-D-erythro-pentofuranosyl)-6-(trifluoromethyl)purine}

Synthesis was performed using a modification of an established method $(23,24)$. A mixture of 9-[3,5-bis-O-(4-methylbenzoyl)-2-deoxy- $\beta$-D-erythro-pentofuranosyl]-6-iodopurine (300 $\mathrm{mg}, 0.5 \mathrm{mmol})$, (trifluoromethyl) trimethylsilane $\left(\mathrm{CF}_{3} \mathrm{SiMe}_{3}\right)(206 \mu \mathrm{L}, 1.4 \mathrm{mmol})$, potassium fluoride (KF) ( $82 \mathrm{mg}, 1.4 \mathrm{mmol})$, copper iodide (CuI) $(150 \mathrm{mg}, 0.8 \mathrm{mmol})$, dimethylformamide (DMF) $(1 \mathrm{~mL})$ and 1-methyl-2-pyrrolidinone (NMP) $(1 \mathrm{~mL})$ was stirred at $60^{\circ} \mathrm{C}$ for 24 hours. After cooling to room temperature, the solvents were evaporated under low pressure and the residue was chromatographed on a silica gel column in EtOAc/Hexanes 1:4 to 1:1 to give oily 9-[3,5-bis- $O$-(4-methylbenzoyl)-2-deoxy- $\beta$-D-erythro-pentofuranosyl]-6-

trifluoromethylpurine (140 mg, 58\%). This intermediate was de-protected by treatment with $50 \mathrm{ml}$ of $0.2 \mathrm{mM} \mathrm{NaOMe}$ in $\mathrm{MeOH}$ at room temperature for 12 hours. The solvent was evaporated and the residue crystallized from $\mathrm{MeOH} / \mathrm{Toluene} / \mathrm{Heptane}$ to give crystalline title compound ( $78 \mathrm{mg}$, $89 \%$ yield of de-protection, $51 \%$ overall yield). All analytical and spectral data were identical to an authentic sample (23).

\section{Synthesis of 9-(2-Deoxy- $\beta$-D-erythro-pentofuranosyl)-6-methylpurine}

This compound was synthesized by a modification of an established procedure (25-27). Methylmagnesium chloride ( $\mathrm{MeMgCl})(2 \mathrm{~mL}$ of a $3 \mathrm{M}$ solution in tetrahydrofuran (THF)) was added drop-wise to a solution of 9-[3,5-bis- $O$-(4-methylbenzoyl)-2-deoxy- $\beta$-D-erythropentofuranosyl]-6-chloropurine $(848 \mathrm{mg}, 1.67 \mathrm{mmol})$ and iron (III) acetylacetonate (Fe $\left.(\mathrm{acac})_{3}\right)(103 \mathrm{mg}, 0.29 \mathrm{mmol})$ in a mixture of 1-methyl-2-pyrrolidinone (NMP) $(1 \mathrm{~mL})$ and THF $(10 \mathrm{~mL})$ at room temperature under an argon atmosphere. The mixture was then stirred for 2 hours, poured onto a mixture of crushed ice $(100 \mathrm{ml})$ and $\mathrm{NH}_{4} \mathrm{Cl}(1 \mathrm{~g})$ and extracted into EtOAc $(2 \times 100 \mathrm{~mL})$. The combined organic layers were dried over $\mathrm{MgSO}_{4}$ and evaporated. The residue was chromatographed on a silica gel column $(100 \mathrm{~g})$ in EtOAc/Hexanes 1:4 to 1:1 to give oily 9-[3,5-bis- $O$-(4-methylbenzoyl)-2-deoxy- $\beta$-D-erythro-pentofuranosyl]-6methylpurine $(550 \mathrm{mg}, 77 \%)$. This intermediate was de-protected by treatment with $50 \mathrm{~mL}$ of $0.2 \mathrm{mM} \mathrm{NaOMe}$ in $\mathrm{MeOH}$ at room temperature for 12 hours. The solvent was evaporated and the residue crystallized from $\mathrm{MeOH} /$ Toluene/Heptane to give crystalline title compound (295 $\mathrm{mg}, 98 \%$ yield of de-protection, $75 \%$ overall yield). White crystals, m.p. $153-155^{\circ} \mathrm{C} \mathrm{(m.p.}$ reported at $\left.161^{\circ} \mathrm{C}(25,26)\right) .{ }^{1} \mathrm{H}$ NMR $\left(400 \mathrm{MHz}\right.$, DMSO- $\left.d_{6}\right): \delta 8.77(\mathrm{~s}, 1 \mathrm{H}, \mathrm{H}-2) ; 8.73(\mathrm{~s}, 1 \mathrm{H}$, $\mathrm{H}-8) ; 6.45$ (t, $\left.1 \mathrm{H}, J_{1^{\prime}, 2^{\prime}}=7.2,6.3 \mathrm{~Hz}, \mathrm{H}^{\prime} 1^{\prime}\right) ; 5.60$ (br, 1H, OH-3'); 5.20 (br, 1H, OH-5'); 4.45 $\left(\mathrm{m}, 1 \mathrm{H}, \mathrm{H}-3^{\prime}\right) ; 3.88\left(\mathrm{~m}, 1 \mathrm{H}, \mathrm{H}-4^{\prime}\right) ; 3.62\left(\mathrm{dd}, 1 \mathrm{H}, J_{\mathrm{gem}}=11.8 \mathrm{~Hz}, J_{5^{\prime} \mathrm{a}, 4^{\prime}}=4.6 \mathrm{~Hz}, \mathrm{H}-5^{\prime} \mathrm{a}\right) ; 3.53$ $\left(\mathrm{dd}, 1 \mathrm{H}, J_{\text {gem }}=11.8 \mathrm{~Hz}, J_{5^{\prime} \mathrm{b}, 4^{\prime}}=4.5 \mathrm{~Hz}, \mathrm{H}-5^{\prime} \mathrm{b}\right) ; 2.76\left(\mathrm{ddd}, 1 \mathrm{H}, J_{\text {gem }}=13.3 \mathrm{~Hz}, J_{2^{\prime} \mathrm{a}, 1^{\prime}}=7.2\right.$ $\left.\mathrm{Hz}, J_{2^{\prime} \mathrm{a}, 3^{\prime}}=6.0 \mathrm{~Hz}, \mathrm{H}-2^{\prime} \mathrm{a}\right) ; 2.71\left(\mathrm{~s}, 3 \mathrm{H}, \mathrm{CH}_{3}\right) ; 2.33\left(\mathrm{ddd}, 1 \mathrm{H}, J_{\mathrm{gem}}=13.3 \mathrm{~Hz}, J_{2^{\prime} \mathrm{b}, 1^{\prime}}=6.3 \mathrm{~Hz}\right.$, $\left.J_{2^{\prime} \mathrm{b}, 3^{\prime}}=3.7 \mathrm{~Hz}, \mathrm{H}-2^{\prime} \mathrm{b}\right)$. MS (MALDI+): $251\left([\mathrm{M}+\mathrm{H}]^{+}\right.$calc. 251).

\section{Synthesis of 2'-deoxyribofuranoside triphosphates}

Phosphorylation was achieved via the protocol of Ludwig using phosphorus oxychloride and tributylammonium pyrophosphate (19). Briefly, nucleosides were dried under vacuum then added to cold, freshly distilled $\mathrm{PO}(\mathrm{OMe})_{3}$ (Approximately $1 \mathrm{~mL}$ of a $40 \mathrm{mM}$ solution) before adding 1.5 eq of $\mathrm{POCl}_{3}(99.999 \%$, Aldrich). After stirring on ice overnight, the solution was warmed to room temperature and 5 eq of tributylammonium pyrophosphate (anhydrous, Sigma) as a $1 \mathrm{M}$ solution in dry dimethylformamide (DMF) was added and allowed to react for approximately 30 minutes. Triethylammonium bicarbonate (TEAB) (5 mL of $0.1 \mathrm{M}$ solution) was added to quench the reaction. The resulting product solution was then diluted to $200 \mathrm{~mL}$ and added directly to a TEAB-equilibrated ion-exchange column (Sephadex-DEAE A-25, Aldrich) and eluted using a 0 to $1 \mathrm{M}$ TEAB gradient. Fractions were individually spotted on a 
MALDI plate with 2,4,6-Trihydroxyacetophenone (THAP) as the matrix, and triphosphate fractions identified by their $\mathrm{MALDI}^{-} 1$ peak (negative ion mode). Triphosphate fractions were collected, dried (with the aid of EtOH to help remove triethylamine), and purified by HPLC using a 50 minute gradient of 0 to $60 \% \mathrm{MeCN}$ in $20 \mathrm{mM}$ triethylammonium acetate (TEAA, $\mathrm{pH}$ 7.5). For the analogue triphosphates containing the bases purine, 6-methylpurine, and 6trifluoromethylpurine, the solvent contained $100 \mathrm{mM}$ TEAA.

\section{Synthesis of 1- $\beta-D-2$ '-Deoxyribofuranosyl-(4-aminobenzimidazole)-5'-triphosphate (d4ABTP)}

1,2-Diamino-3-nitrobenzene ( $400 \mathrm{mg}, 3 \mathrm{mmol}$, Aldrich) was dissolved in $20 \mathrm{~mL} 97 \%$ formic acid $\left(100 \mathrm{mM}\right.$ solution) and refluxed at $110^{\circ} \mathrm{C}$ overnight. The dark solution was filtered through Celite and dried under vacuum, dissolved in $40 \mathrm{~mL}$ of water, then extracted with EtOAc $(3 \times$ $150 \mathrm{~mL}$ ). The combined organic layers were dried using $\mathrm{MgSO}_{4}$ and reduced to dryness under vacuum (70\% yield; used without further purification). ${ }^{1} \mathrm{H}$ NMR $\left(300 \mathrm{MHz}\right.$, DMSO- $d_{6}$,): $\delta$ $8.44\left(1 \mathrm{H}, \mathrm{s}, \mathrm{C}_{2} \mathrm{H}\right) ; 8.15\left(2 \mathrm{H}, \mathrm{br} \mathrm{d}, J_{\text {gem }}=4.8 \mathrm{~Hz}, \mathrm{ArH}\right) ; 7.40\left(1 \mathrm{H}, \mathrm{dd}, J_{g e m l, 2}=4.8 \mathrm{~Hz}, \mathrm{ArH}\right)$. 4-Nitrobenzimidazole was converted into the nucleoside and nucleoside triphosphates as described earlier. 1-(2-Deoxy- $\beta$-D-erythro-pentofuranosyl)-4-nitrobenzimidazole: ${ }^{1} \mathrm{H}$ NMR $\left(500 \mathrm{MHz}\right.$, Acetone- $\left.d_{6}\right): \delta 8.63\left(1 \mathrm{H}, \mathrm{s}, \mathrm{C}_{2} \mathrm{H}\right) ; 8.17\left(1 \mathrm{H}, \mathrm{d}, J_{g e m}=8.5 \mathrm{~Hz}, J_{v i c}=0.5 \mathrm{~Hz}, \mathrm{ArH}\right)$; $8.02\left(1 \mathrm{H}, \mathrm{d}, J_{\text {gem }}=8.0 \mathrm{~Hz}, J_{\text {vic }}=0.5 \mathrm{~Hz}, \mathrm{ArH}\right) ; 7.44\left(1 \mathrm{H}, \mathrm{dd}, J_{\text {gem } 1,2}=8.0 \mathrm{~Hz}, \mathrm{ArH}\right) ; 6.49$ $\left(1 \mathrm{H}, \mathrm{dd}, J_{1^{\prime}, 2^{\prime}}=6.5 \mathrm{~Hz}, 7.0 \mathrm{~Hz}, \mathrm{H}-1^{\prime}\right) ; 4.64\left(1 \mathrm{H}, \mathrm{m}, \mathrm{H}-3^{\prime}\right) ; 4.03\left(1 \mathrm{H}, \mathrm{m}, \mathrm{H}-4^{\prime}\right) ; 3.76(2 \mathrm{H}, \mathrm{m}$, H-5'); 2.72 (1H, m, H-2'b); 2.51 (1H, m, H-2'a). MS (MALDI+): 302 ([M+Na ${ }^{+}$calc. 302). 1$\beta$-D-2'-Deoxyribofuranosyl-(4-nitrobenzimidazole)-5'-triphosphate ( $\left.\mathrm{d} \mathrm{NO}_{2} \mathrm{BTP}\right):{ }^{31} \mathrm{P}$ NMR (400 MHz, $\mathrm{D}_{2} \mathrm{O}$ ): $\delta-10.1$ (br d, $\gamma-\mathrm{P}$ ); -10.8 (br d, $\alpha-\mathrm{P}$ ); -22.5 (br m, $\beta$-P). MS (MALDI-): $518\left([\mathrm{M}-\mathrm{H}]^{-}\right.$calc. 518$)$. To $500 \mu \mathrm{L}$ of $15 \mathrm{mM} \mathrm{d} 4 \mathrm{NO}_{2} \mathrm{BTP}$ was added $15 \mathrm{mg}$ of $10 \%$ palladium on carbon $(\mathrm{Pd} / \mathrm{C})$. While stirring, $1 \mathrm{~atm}$ (balloon) of $\mathrm{H}_{2}$ was applied for three hours at room temperature to effect complete conversion to $1-\beta-\mathrm{D}-2^{\prime}$-deoxyribofuranosyl-(4aminobenzimidazole)-5'-triphosphate (d4ABTP). ${ }^{31} \mathrm{P}$ NMR (400 MHz, $\left.\mathrm{D}_{2} \mathrm{O}\right): \delta-4.66$ (br, $\gamma$ P); -9.76 (br, $\alpha-\mathrm{P}) ;-18.3$ (br, $\beta-\mathrm{P})$. MS (MALDI-): 488 ([M-H] ${ }^{-}$calc. 488 ).

9- $\beta$-D-2'-Deoxyribofuranosyl-(1-deazapurine)-5'-triphosphate (d1DPTP): ${ }^{31} \mathrm{P}$ NMR (400 $\mathrm{MHz}, \mathrm{D}_{2} \mathrm{O}$ ): $\delta-8.52$ (br, $\left.\gamma-\mathrm{P}\right) ; 10.5(\mathrm{~d}, \alpha-\mathrm{P}) ; 21.8$ (br, $\left.\beta-\mathrm{P}\right)$. MS (MALDI-): 474 ([M-H] ${ }^{-}$calc. 474).

9- $\beta$-D-2'-Deoxyribofuranosyl-(3-deazapurine)-5'-triphosphate (d3DPTP): ${ }^{31} \mathrm{P}$ NMR (400 $\left.\mathrm{MHz}, \mathrm{D}_{2} \mathrm{O}\right): \delta-7.05$ (d, $\left.\gamma-\mathrm{P}\right) ;-10.1$ (d, $\left.\alpha-\mathrm{P}\right) ;-20.6(\mathrm{dd}, \beta-\mathrm{P})$. MS (MALDI-): 474 ([M-H] ${ }^{-}$ calc. 474).

9- $\beta$-D-2'-Deoxyribofuranosyl-(purine)-5'-triphosphate (dPTP): ${ }^{31} \mathrm{P}$ NMR $\left(400 \mathrm{MHz}, \mathrm{D}_{2} \mathrm{O}\right): \delta$ -9.91 (d, $\gamma-\mathrm{P}) ;-10.6$ (d, $\alpha-\mathrm{P}) ;-22.3$ (t, $\beta$-P). MS (MALDI-): 475 ([M-H] $]^{-}$calc. 475).

9- $\beta$-D-2'-Deoxyribofuranosyl-(6-Methylpurine)-5'-triphosphate (d6MPTP): ${ }^{31} \mathrm{P}$ NMR (400 $\mathrm{MHz}, \mathrm{D}_{2} \mathrm{O}$ ): $\delta-5.05$ (br, $\left.\gamma-\mathrm{P}\right) ;-9.96(\mathrm{~d}, \alpha-\mathrm{P}) ;-19.5$ (br, $\left.\beta-\mathrm{P}\right)$. MS (MALDI-): 489 ([M-H] ${ }^{-}$ calc. 489$)$.

9- $\beta$-D-2'-Deoxyribofuranosyl-(6-Trifluoromethylpurine)-5'-triphosphate $\left(\mathrm{d}_{6} \mathrm{~F}_{3} \mathrm{PTP}\right):{ }^{31} \mathrm{P}$ NMR (400 MHz, $\left.\mathrm{D}_{2} \mathrm{O}\right): \delta-5.99$ (br, $\left.\gamma-\mathrm{P}\right) ;-10.1$ (br, $\left.\alpha-\mathrm{P}\right) ;-19.6$ (br, $\left.\beta-\mathrm{P}\right)$. MS (MALDI-): $543\left([\mathrm{M}-\mathrm{H}]^{-}\right.$calc. 543$)$.

9- $\beta$-D-2'-Deoxyribofuranosyl-(1-deazaadenine)-5'-triphosphate (d1DATP): ${ }^{31} \mathrm{P}$ NMR (400 $\left.\mathrm{MHz}, \mathrm{D}_{2} \mathrm{O}\right): \delta-9.29(\mathrm{br}, \gamma-\mathrm{P}) ;-10.6(\mathrm{~d}, \alpha-\mathrm{P}) ;-22.0(\mathrm{br}, \beta-\mathrm{P})$. MS (MALDI-): $489\left([\mathrm{M}-\mathrm{H}]^{-}\right.$ calc. 489$)$. 


\section{5 '-end labeling of primers and annealing of primer-templates}

DNA primers were HPLC purified, ${ }^{32} \mathrm{P}$ labeled at the $5^{\prime}$-end using $\left[\gamma_{-}{ }^{32} \mathrm{P}\right]$ ATP and polynucleotide kinase, and annealed to each of the four templates as previously described $(28,29)$.

\section{Polymerization Assays}

Steady state assays contained $1 \mu \mathrm{M} 5^{\prime}\left[{ }^{32} \mathrm{P}\right]$ primer-template, $10 \mathrm{mM} \mathrm{MgCl}_{2}, 50 \mathrm{mM}$ Tris- $\mathrm{HCl}$ (pH 7.6), $1 \mathrm{mM}$ dithiothreitol, $0.05 \mathrm{mg} / \mathrm{mL}$ bovine serum albumin, and various concentrations of natural or analog dNTPs in a total volume of 5 or $10 \mu \mathrm{L}$. Reactions were initiated by adding enzyme, incubated at $37{ }^{\circ} \mathrm{C}$, and quenched by adding $5 \mu \mathrm{L}$ of gel loading buffer ( $90 \%$ formamide in $1 \mathrm{X}$ Tris/Borate/EDTA buffer, $0.05 \%$ xylene cyanol and bromophenol blue). Products were separated by denaturing gel electrophoresis (20\% acrylamide, $8 \mathrm{M}$ urea) and analyzed by phosphorimagery (Molecular Dynamics). Kinetic parameters were determined by fitting the data to the Michaelis-Menten equation using KaleidaGraph software. All rates were normalized to the same final enzyme concentration $(2 \mathrm{nM})$.

\section{Polymerase Read-Through Assays}

The ability of pol $\alpha$ to elongate past a newly incorporated analogue was determined under steady-state conditions. Six analogue-dNTPs (d3DATP, dPTP, d6MPTP, d3DPTP, d1DPTP, and d4ABTP, see Figure 1) and dATP were each incorporated separately by Klenow fragment onto the 3'-end of a primer-template $\left(\mathrm{DNA}_{\mathrm{T}}\right.$, see Figure 2) to make a series of "primerXtemplates". Depending upon the ability of Klenow fragment to polymerize the analogue, each reaction was incubated for 5-50 minutes and contained 5-25 units of exo ${ }^{-}$Klenow fragment (New England Biolabs), 100-1000 $\mu \mathrm{M}$ dNTP analogue, $10 \mathrm{mM} \mathrm{MgCl}_{2}, 50 \mathrm{mM}$ Tris- $\mathrm{HCl}$ (pH 7.6), $1 \mathrm{mM}$ dithiothreitol, $0.05 \mathrm{mg} / \mathrm{ml}$ bovine serum albumin, and $60 \mu \mathrm{M} \mathrm{DNA}_{\mathrm{T}}$. Each of these "primerX's" were gel purified under denaturing conditions (8M urea, $20 \%$ acrylamide), extracted overnight into water, and subsequently re-annealed to $\mathrm{DNA}_{\mathrm{T}}$. An eighth primerXtemplate, containing 1-deazadA at the primer terminus, was generated using pol $\alpha$ under analogous conditions.

Using these "primerX-templates", we measured incorporation of the next-correct dNTP (dTTP) and the subsequent, second-correct dNTP (dATP) under assay conditions similar to those described above. For the latter, a "running-start"-type analysis was employed (30); we varied the concentration of dATP while keeping the concentration of dTTP static $(100 \mu \mathrm{M})$. Kinetic parameters were determined by fitting the data to the Michaelis-Menten equation using KaleidaGraph software.

\section{Determination of LogP}

We measured $\log \mathrm{P}$ using 1-octanol as the organic phase (31). The free bases were dissolved in 1-octanol saturated with water or vice versa, depending on which solvent dissolved the solute best, and their extinction coefficients determined. Aided by UV spectroscopy, the volume ratio of 1-octanol/water required to separate equal amounts of solute into each phase was determined in order to calculate the value P. For each free base, $\mathrm{P}$ values were calculated at three different solute concentrations (a 10-fold range) and an average taken before calculating the final $\log \mathrm{P}$ value. Each base was analyzed under neutral conditions (Using $0.1 \mathrm{~N} \mathrm{NaOH}$ or $0.1 \mathrm{~N} \mathrm{HCl}$ ). Observed wavelengths for each base (same as $\lambda$ max): benzimidazole (B), $244 \mathrm{~nm}$; 1-deaza-6methylpurine (Q), $280 \mathrm{~nm}$; 4-methylbenzimidazole (Z), $248 \mathrm{~nm}$; 1-deazapurine (1DP), 282 $\mathrm{nm}$; 3-deazapurine (3DP), $264 \mathrm{~nm}$; 6-methylpurine (6MP), $262 \mathrm{~nm}$; purine $(\mathrm{P}), 264 \mathrm{~nm}$; 4aminobenzimidazole (4AB), $262 \mathrm{~nm}$; 6-trifluoromethylpurine $\left(6 \mathrm{~F}_{3} \mathrm{P}\right), 273 \mathrm{~nm}$; 4trifluoromethylbenzimidazole $\left(4 \mathrm{~F}_{3} \mathrm{~B}\right), 252 \mathrm{~nm}$; adenine $(\mathrm{A}), 260 \mathrm{~nm}$; 1-deazaadenine (1DA), $266 \mathrm{~nm}$. 


\section{Results}

Previous studies showed that pol $\alpha$ readily polymerizes dNTP analogues whose base size, shape and chemical features do not closely resemble a canonical base $(11,12)$. These dNTP analogues, which will be referred to as low fidelity dNTPs, contain bases such as benzimidazole, 4methylbenzimidazole and 5,6-dinitrobenzimidazole and are readily polymerized opposite all 4 natural bases. In order to discover why pol $\alpha$ incorporates these low fidelity dNTP analogues so efficiently, we asked two questions; (i) what features have to be removed from a high fidelity base such as adenine (or guanine) to convert it into a low fidelity base (i.e., it is more readily misincorporated opposite A, C and G (or T, A and G)), and; (ii) what features have to be added to a low fidelity base to convert it into a high fidelity base (i.e., it is not readily incorporated opposite natural bases in the template)? Using the analogues and natural bases shown in Figure 1 , we examined the effect of "mutating" specific atoms on both high fidelity bases (adenine and guanine) and low fidelity bases (benzimidazole, 4-methylbenzimidazole, and 4trifluoromethylbenzimidazole). To minimize the possibility that the results of the change were base specific, we examined the effects of altering specific atoms within the context of multiple base analogues. Importantly, each of the analogous atomic replacements gave similar results with all of the bases tested (see below).

Synthetic primer-templates of defined sequence were used to analyze the incorporation of analogue and natural dNTPs opposite the four natural bases. In order to minimize the possibility that the DNA sequence around the template base being copied would influence results, we measured polymerization of dNTPs across from all four natural bases in essentially the same sequence context (Figure 2). For one of the four templates $\left(\mathrm{DNA}_{\mathrm{A}}\right)$, one additional base in the single-stranded template had to be altered in order to prevent insertion of two consecutive dTTPs. We determined $\mathrm{V}_{\mathrm{MAX}}$ and $\mathrm{K}_{\mathrm{M}}$ for incorporation of natural dNTPs opposite their natural template partners (Table 1) and analogue dNTPs, along with dATP and dGTP, opposite all four natural templates (Table 2). As expected based on previous data, pol $\alpha$ polymerized dATP and dGTP opposite an incorrect base several orders of magnitude slower than opposite the correct template base (12).

\section{N-3 helps pol $\alpha$ discriminate between right and wrong dNTPs}

We first examined the effect of removing $\mathrm{N}-3$ from the two high fidelity bases adenine and guanine (Table 2). During correct incorporation, removing N-3 decreases the efficiency of incorporation by 2-fold for 3-deazaadenine and 5-fold for 3-deazaguanine. As compared to misincorporation of dATP and dGTP, removing N-3 decreases fidelity opposite some bases, but has relatively little effect opposite others. However, if one compares the efficiency with which pol $\alpha$ correctly incorporates 3-deaza-dATP and 3-deaza-dGTP with the rates at which it incorrectly incorporates these dNTPs, removing N-3 significantly reduces fidelity across the board due to the lower efficiency of correct incorporation of the 3-deaza-dNTPs compared to the natural dNTPs.

Since removing N-3 from high fidelity bases decreases fidelity, we tested the hypothesis that adding N-3 back to low-fidelity bases would increase fidelity (Figure 3, Table 2). Pol $\alpha$ discriminates relatively poorly against polymerization of benzimidazole-dNTP and 4methylbenzimidazole-dNTP across from all four natural bases. (Discrimination is defined as $\mathrm{V}_{\mathrm{MAX}} / \mathrm{K}_{\mathrm{M}}$ for polymerization of the correct, natural dNTP divided by $\mathrm{Vmax} / \mathrm{Km}$ for polymerization of an analogue or incorrect, natural dNTP.) Upon adding back the equivalent of a purine $\mathrm{N}-3$, however, pol $\alpha$ now discriminates against polymerization of the resulting 1deazapurine-dNTP and 1-deaza-6-methylpurine-dNTP much more efficiently. Thus, for both high and low fidelity bases, N-3 appears to be important for maintaining fidelity. 


\section{N-1 also helps pol $\alpha$ discriminate between right and wrong dNTPs}

Adding N-1 to 1-deazadATP (d1DATP), thereby generating dATP, increases incorporation opposite $\mathrm{T}$ by 20 -fold (Figure 4 , Table 2 ), but has relatively small effects on the incorporation opposite A, C, and G as compared to dATP. In contrast, adding back N-1 to 3 bases of lower than normal fidelity (benzimidazole, 1-deazapurine, and 1-deaza-6-methylpurine, to generate 3-deazapurine, purine, and 6-methylpurine, respectively), significantly enhances the ability of pol $\alpha$ to identify dNTPs containing the resulting analogues as wrong for polymerization opposite either A, C, or G. Concomitantly, adding back N-1 greatly enhanced polymerization opposite T. In each of these 3 bases that contained N-1, 3-deazapurine, purine, and 6methylpurine, the hybridization state of $\mathrm{N}-1$ will allow formation of a Watson-Crick hydrogen bond with $\mathrm{HN}-3$ of $\mathrm{T}$.

The roles of N-1 and N-3 were also examined by comparing 4-trifluoromethylbenzimidazoledNTP with 6-trifluoromethylpurine-dNTP (Figure 5, Table 2). Consistent with the results described above, adding back these groups greatly enhanced the ability of pol $\alpha$ to discriminate against polymerization of 6-trifluoromethylpurine-dNTP opposite A, C, and G. Indeed, pol $\alpha$ discriminates against polymerization of 6-trifluoromethylpurine-dNTP much more strongly than natural dNTPs. Comparatively, pol $\alpha$ polymerized 6-trifluoromethylpurine-dNTP opposite $\mathrm{T}$ relatively efficiently.

\section{The exocyclic amino group at C-6 primarily enhances polymerization opposite $\mathbf{T}$}

As is the case for $\mathrm{N}-1$, the exocyclic amino group at C-6 (N-6) can form a hydrogen bond with $\mathrm{T}$. Incorporation opposite T increases 10- to 20-fold upon adding N-6 to 3-deazapurines (Figure 6 , Table 2), and this rate increases 35 -fold when added to 1-deazapurine and 1-deaza-6methylpurine. However, unlike N-1, adding N-6 does not significantly influence incorporation rates opposite templates A, C, or G. Upon averaging the discrimination numbers obtained opposite these three templates, adding N-6 to 1-deaza-6-methylpurine and to 4methylbenzimidazole (generating 1-deazaadenine and 4-aminobenzimidazole, respectively), only increases discrimination by 2 to 3 fold. However, in all other cases when adding N-6 (i.e. converting 1-deazapurine, 3-deazapurine, and benzimidazole to 1-deazaadenine, 3deazaadenine, and 4-aminobenzimidazole, respectively), discrimination does not significantly increase and even decreases slightly in the case of 3-deazaadenine versus 3-deazapurine (Table 2). Overall, the average discrimination against polymerization opposite $\mathrm{A}, \mathrm{C}$, and $\mathrm{G}$ rarely increases more than 2 -fold and decreases by no more than 3 -fold (in a single case) upon adding N-6. In contrast, adding N-1 or N-3 consistently and often times dramatically increase discrimination, frequently by 10 fold or more (Table 2, Figure 3, Figure 4). Thus, N-6 most likely has one primary role, helping pol $\alpha$ positively identify a dNTP for polymerization opposite its correct base partner (as opposed to helping pol $\alpha$ identify the incoming dNTP as wrong).

\section{Requirements for efficient polymerization of the next correct dNTP onto adenine analogues}

We generated a series of primer templates where the $3^{\prime}$ terminal nucleotide on the primer contained either adenine or an adenine analogue, and measured polymerization of dTTP, the next correct dNTP (Table 3). Removing a single Watson-Crick hydrogen-bonding group reduces the efficiency of dTTP polymerization, while removal of both N-1 and N-6 severely impaired dTTP incorporation. The loss of N-3 also inhibited dTTP polymerization, but to a lesser extent than the loss of either N-1 or N-6. 


\section{Requirements for efficient polymerization of the second correct dNTP onto adenine analogues}

We used the "running start" methodology pioneered by Goodman and coworkers to measure polymerization of the second correct dNTP onto primer-templates (Table 4). Assays contained a primer-template whose 3 '-terminal nucleotide was either adenine or an adenine analogue, dTTP, and varying concentrations of dATP. Under these conditions, pol $\alpha$ can polymerize up to 2 nucleotides onto the primer terminus. Having a base at the primer terminus that could only form one Watson-Crick hydrogen bond with the template $\mathrm{T}$ (i.e. purine, 6-methylpurine, and 1-deazaadenine), resulted in only small effects on polymerization of the second correct dNTP. However, the absence of N-3 at the primer terminus (either 3-deazaadenine or 3-deazapurine) greatly impaired polymerization of the second correct dNTP.

In those cases where pol $\alpha$ could efficiently add the second correct dNTP, we qualitatively examined further polymerization by also including dGTP in the assays to potentially allow polymerization to the end of the template. Figure 7 shows that the absence of one of the WatsonCrick hydrogen bonds at the primer terminus did not significantly impede polymerization of the third or latter dNTPs, although there are some differences. Most notably, the strong pause site observed at the primer +9 position observed with either adenine, purine, or 1-deazaadenine at the primer terminus is not observed with 6-methylpurine at the primer terminus.

\section{Hydrophobicity does not correlate with fidelity}

We calculated the hydrophobicity parameter, $\log \mathrm{P}$, of each of the bases of Figure 1 (except 3deazaadenine, 3-deazaguanine, and guanine) and compared these values with the ability of pol $\alpha$ to identify corresponding dNTPs as wrong. Since many of the analogues can form a WatsonCrick hydrogen bond(s) with T and, therefore, can be considered as dATP analogues, we defined wrong as polymerization opposite A, C, and G. Figure 8 shows that the ability of pol $\alpha$ to discriminate against polymerization of the analogues does not closely correlate with hydrophobicity, consistent with the results of previous studies (11). While the more hydrophobic bases tend to give dNTPs with lower fidelity, there are multiple exceptions to this trend.

\section{Discussion}

Using a series of dNTP analogues, we have identified the features of an incoming purine dNTP that pol $\alpha$ uses to identify it as either right or wrong. Pol $\alpha$ uses both $\mathrm{N}-1$ and $\mathrm{N}-3$ to prevent misincorporation, while it uses $\mathrm{N}-1$ and the exocyclic amine at C-6 (N-6) to enhance correct incorporation opposite T. After incorporation of a nucleotide, however, the correct geometry of the base-pair at the primer $3^{\prime}$-terminus appears critical for rapid polymerization of additional dNTPs.

Two sets of data demonstrated the importance of N-3 for fidelity - removing it from the high fidelity bases adenine and guanine reduced fidelity, and adding back N-3 to the low fidelity bases benzimidazole, 4-methylbenzimidazole, and 4-trifluoromethylbenzimidazole (although, in the latter case $\mathrm{N}-1$ was simultaneously added back) significantly enhanced the ability of the polymerase to identify the resulting analogues as wrong. These data indicate that $\mathrm{N}-3$ contributes a factor of around $5-20$ to the fidelity of pol $\alpha^{2}$.

\footnotetext{
${ }^{2}$ The amount of fidelity lost or gained by removing or adding N-3, respectively, depends on how one looks at the data. Comparing the misincorporation rates versus the correct polymerization rates of 3-deazadATP and 3-deazadGTP reveals a larger loss of fidelity upon removing N-3 than comparing misincorporation rates of 3-deazadATP and 3-deazadGTP versus the correct polymerization rates of dATP and dGTP. This results from the slower correct polymerization of the 3-deaza-dNTPs.
} 
A key question is how pol $\alpha$ uses N-3 to identify an incoming purine dNTP as wrong. Since $\mathrm{N}-3$ enhances the ability of pol $\alpha$ to identify as wrong bases that cannot form Watson-Crick hydrogen bonds (ex. Benzimidazole and 4-methylbenzimidazole), the effects of N-3 cannot be due to electronic effects on Watson-Crick hydrogen bonding groups. Alternatively, pol $\alpha$ may directly interact with N-3. Presently, no high-resolution structures of the active site of pol $\alpha$ exist, although the structures of two other B-family polymerases, RB69 and herpes DNA polymerase, have been solved $(32,33)$. Importantly, the active site region of pol $\alpha, \mathrm{RB} 69$, and herpes DNA polymerases that interact with the incipient base-pair between the incoming dNTP and template base exhibit remarkable homology, suggesting that they will have very similar structures (Table 5 (34)). While only the apoenzyme form of herpes DNA polymerase has been solved, the structure of both the apoenzyme and E-DNA-dNTP forms of RB69 polymerase has been solved $(32,35)$. In the ternary complex, dTTP forms a correct base pair with a template adenine and is presumably poised for incorporation. Interestingly, O-2 of the thymine sits just above the edge of Y567 (the equivalent of Y957 in pol $\alpha$ ). Since N-3 of a purine and O-2 of a pyrimidine share similar locations in a correct base pair, N-3 will presumably also be located just above this tyrosine (Figure 9). Significantly, the edge of tyrosine is electron deficient and $\mathrm{O}-2$ of a pyrimidine and N-3 of a purine are both electron rich, allowing for a very favorable interaction (36). Thus, we suspect that interactions between $\mathrm{N}-3$ and this tyrosine serve to enhance the fidelity of pol $\alpha$. Indeed, mutational studies of this tyrosine in RB69 polymerase also support an interaction between these groups (37). Converting Y567 to alanine in RB69 polymerase had only small effects on polymerization of a correct dNTP (5-fold, $\mathrm{V}_{\mathrm{MAX}} \mathrm{K}_{\mathrm{M}}$ ), but decreased fidelity from none to 180 -fold depending upon the mismatch. Strikingly, these results are qualitatively identical to the effects of converting N-3 of a purine dNTP into a C-H group (small effect on correct dNTP polymerization, often large and mismatch dependent decreases in fidelity).

Pol $\alpha$ uses N-1 both to discriminate against wrong dNTPs and to enhance polymerization opposite T. Adding the equivalent of $\mathrm{N}-1$ to either benzimidazole, 4 -aminobenzimidazole, or 1-deaza-6-methylpurine significantly enhanced the ability of pol $\alpha$ to identify the resulting dNTPs as wrong opposite A, C and G. The presence of $\mathrm{N}-1$ also greatly increased the efficiency with which pol $\alpha$ polymerized the various analogues opposite T. Presumably, this reflects the formation of a Watson-Crick hydrogen bond between the purine N-1 and HN-3 of thymine. In each of the analogues tested, N-1 will act as a hydrogen bond acceptor.

The effects of N-1 and N-3 on discrimination against wrong dNTPs do not appear to be additive. Adding either N-1 or N-3 to benzimidazole and generating 1-deazapurine- and 3-deazapurinedNTP, respectively, similarly decreased polymerization opposite A, C, and G. Simultaneously adding back both $\mathrm{N}-1$ and $\mathrm{N}-3$ to benzimidazole to generate purine-dNTP resulted in a level of discrimination much less than one would predict if these effects were additive. Similar lessthan-additive effects are observed for adding back N-1 and N-3 to 4-aminobenzimidazole. Analogously, removing N-3 from adenine had smaller effects on fidelity when compared to the changes observed upon adding N-3 to the benzimidazole derivatives. Thus, pol $\alpha$ can use either N-1 or N-3 to prevent misincorporation, and the functional redundancy may serve to simply ensure high fidelity.

Unlike $\mathrm{N}-1$ and $\mathrm{N}-3$ that help pol $\alpha$ identify an incoming dNTP as wrong, N-6 appears to primarily serve to identify the incoming dNTP as right opposite T. Adding N-6 to either purine or 1-deazapurine did not increase pol $\alpha$ 's ability to identify the resulting dATP or 1-deazadATP as wrong opposite A, C and G, but significantly enhanced polymerization opposite T. Similarly, adding the equivalent of N-6 to benzimidazole, thereby generating 4-

aminobenzimidazole-dNTP, did not enhance pol $\alpha$ 's ability to identify the resulting base as wrong. Somewhat surprisingly, pol $\alpha$ did not preferentially incorporate this dNTP opposite T. This case is slightly more complicated, however, because the absence of both N-1 and N-3 has 
a large affect on the chemical properties of N-6. Adenine's N-6 is a hydrogen bond donor. However, in aqueous solution, removing N-1 and N-3 from adenine (generating 4aminobenzimidazole) changes the pKa of the N-6 group to approximately 4.4 and effectively turning this group into a hydrogen bond acceptor at physiological $\mathrm{pH}$ (Unpublished data, $\mathrm{J}$. Beckman and R. Kuchta).

Together these data indicate that pol $\alpha$ uses a combination of positive and negative selectivity to accurately incorporate purine dNTPs. The presence of N-1 and/or N-3 allow pol $\alpha$ to identify an incoming dNTP as wrong, while N-1 and N-6 (of adenine) allow pol $\alpha$ to identify the incoming dNTP as right opposite T. As described in greater detail below, pol $\alpha$ specifically does not use the shape of the incipient base pair to identify it as right. Importantly, this model can accommodate all published data on the fidelity of pol $\alpha$ and other family B polymerases with natural and synthetic dNTPs. The relatively rapid and unselective polymerization of dNTPs containing bases that neither resemble the shape of a correct base nor form WatsonCrick hydrogen bonds (ex. 5-nitrobenzimidazole, 5-methoxybenzimidazole, and 5,6dinitrobenzimidazole $(11,12)$ ) opposite both canonical and unnatural template bases results from their lacking the chemical features needed for pol $\alpha$ to identify them as wrong. Similarly, the high fidelity of natural dNTPs opposite both canonical and unnatural template bases (5and 6-nitrobenzimidazole (12)) results from these bases containing negative selectors preventing misincorporation and the positive selectors specifying the template base opposite which the incoming dNTP should be polymerized.

Importantly, shape is not directly used by pol $\alpha$ as either a negative or positive selector. Pol $\alpha$ readily misincorporates dNTPs whose bases are similar in shape to adenine (ex. benzimidazole, 4-methylbenzimidazole, 4-trifluoromethylbenzimidazole, and 4aminobenzimidazole) as well as dNTPs whose base shapes are very different than adenine (ex. 5,6-dinitrobenzimidazole). Changes that will have minimal effects on shape, replacing two carbons with nitrogen, greatly improve fidelity. The negligible importance of shape is shown explicitly in Table 6. Since, with the exception of dGTP and d3DGTP, all of the dNTPs tested can be viewed as dATP analogues, we have compared the efficiency of polymerization opposite either $\mathrm{C}$ or $\mathrm{T}$, the potential shape complements of purines. Whereas how closely the base resembles adenine does not predict the efficiency of polymerization opposite $\mathrm{T}$ versus $\mathrm{C}, \mathrm{N}-1$, N-3 and N-6 do predict whether or not pol $\alpha$ will recognize the dNTP analogue as dATP. Thus, pol $\alpha$ presumably uses specific chemical properties of these nitrogens to identify a base as wrong.

Mechanistically, how might pol $\alpha$ use these positive and negative selectors to identify an incoming dNTP as wrong or right? The relatively non-specific incorporation of dNTPs lacking $\mathrm{N}-1$ and N-3 indicates that after these dNTPs bind, the enzyme can readily adopt a catalytically active conformation, even though the bases of the template and incoming dNTP cannot form a correctly shaped base-pair (For example, the relatively rapid polymerization of 5,6dinitrobenzimidazole, 5-nitroindole, or 4-methylbenzimidazole opposite $A$ and $G((11,12)$ and Table 2, respectively)). Upon adding back either N-1 or N-3 to the unnatural base, pol $\alpha$ adopts a catalytically active conformation much less readily. Potentially, this could occur if the free electron pair of the nitrogen either blocked a needed conformational change or prevented the unnatural base from finding an unobtrusive pocket that allowed catalysis. The positive selectors, N-1 and N-6 of adenine, would then serve to overcome the effects of the negative selectors when the appropriate template base, thymine, is present. For example, by enhancing the formation of a Watson-Crick base pair, the positive selectors would remove the negative selectors from positions that blocks polymerization (i.e., when opposite a wrong template base) and into a position that allows formation of a catalytically active enzyme. This effect can also be viewed as an indirect readout of base-pair shape. Formation of a correctly shaped base-pair will necessarily remove $\mathrm{N}-1$ and $\mathrm{N}-3$ from any location that can inhibit dNTP polymerization, 
while formation of an incorrectly shaped base-pair will leave N-1 and N-3 in positions that inhibit polymerization.

In contrast to the lack of shape selectivity during the dNTP polymerization reaction, shape appears critical for addition of the next correct dNTP. Previous work showed that polymerases closely related to human pol $\alpha$, drosophila and calf thymus pol $\alpha$, polymerize the next correct dNTP onto mismatches $10^{3}$ - to $10^{5}$-fold more slowly than onto a correct base-pair $(38,39)$.

Analogously, after incorporating an unnatural base lacking the ability to form Watson-Crick hydrogen bonds (ex. 5-methoxybenzimidazole and 5,6-dinitrobenzimidazole (11) or 1deazapurine and 4-aminobenzimidazole, Table 2), pol $\alpha$ polymerizes the next correct dNTP at similar slow rates. However, upon adding back groups that can form Watson-Crick hydrogen bond(s) with the template base (For example, analogues with either N-1, both N-3 and N-6, or both $\mathrm{N}-1$ and N-6, Table 3 and Figure 7), the rate of addition of the next correct dNTP increases dramatically. Presumably, adding back a Watson-Crick hydrogen bond will increase the similarity between the analogue-T base-pair and a natural, correct base-pair, thereby optimizing the position of the $3^{\prime}-\mathrm{OH}$ for rapid polymerization of the next dNTP. As one would predict if pol $\alpha$ is recognizing the shape of the base-pair at the primer terminus, generating a base-pair that contains two Watson-Crick hydrogen bonds enhances polymerization more than a basepair capable of a single bond. Potentially, the slightly slower elongation of the primer containing 3-deaza-adenine rather than adenine could reflect either an interaction between pol $\alpha$ and N-3 or the effect of removing N-3 on the chemical properties of N-1 and/or N-6.

A key feature of the fidelity strategy employed by pol $\alpha$ is using two orthogonal screens. As noted earlier, fidelity of a polymerase results from both usually choosing the right (d)NTP and only slowly elongating the product of wrong incorporation, thereby allowing proofreading. During incorporation, pol $\alpha$ employs a combination of positive and negative selectivity, while for elongation of the newly added nucleotide, pol $\alpha$ uses shape selectivity. A consequence of this strategy is that modified bases that can bypass the first screen are more likely to be detected by the second screen since this latter screen examines a different set of parameters than the first screen. If both screens were based on the same parameter(s), a wrong base that easily bypasses the first screen would just as easily bypass the second screen. While pol $\alpha$ itself lacks $3^{\prime}-5^{\prime}$ exonuclease activity and hence cannot directly proofread, the very slow elongation of misshaped base-pairs presumably allows pol $\alpha$ to dissociate from the DNA and another exonuclease to excise the nucleotide at the primer 3 '-terminus.

Efficient incorporation of the second dNTP onto a primer by pol $\alpha$ clearly requires that an adenine base at the primer terminus contain N-3. Similarly, we found that pol $\alpha$ does not efficiently add the second dNTP if 3-deazaguanine is present at the primer terminus (Unpublished data, J. Beckman and R. Kuchta). Recently, Benner and coworkers demonstrated that two other B-family polymerases, Pfu polymerase and "GB-D" (Deep Vent polymerase) also require N-3 for incorporation of the second dNTP (47). This discrimination most likely results from a requirement for a hydrogen bond between $\mathrm{N}-3$ and a conserved lysine residue. The structure of the RB69 polymerase-DNA complex shows that this hydrogen bond is formed by K706, pol $\alpha$ 's equivalent of K1052 $(35,47)$. The absence of this hydrogen bond presumably prevents pol $\alpha$ from adopting a catalytically active conformation. However, N-3 is not a universal requirement for B-family polymerases, since "Tli" (Vent polymerase) does not require $\mathrm{N}-3$ (47).

It is presently unclear to what extent other polymerase families employ strategies similar to pol $\alpha$. Human and herpes primase appear to require the formation of Watson-Crick hydrogen bonds in order to polymerize a NTP $(6,7)$. Indeed, these enzymes misincorporate the natural NTPs orders of magnitude faster than they will incorporate NTPs containing unnatural bases incapable of Watson-Crick hydrogen bonding with the template, a situation diametrically 
opposed to that for pol $\alpha$. Klenow fragment, an A family polymerase, has been suggested to use shape as the primary determinant for fidelity $(8-10,40-42)$. However, various groups have also shown that $\mathrm{KF}$ will also efficiently incorporate bases whose shape does not resemble a canonical base $(11,12,43-46)$.

Together, the data presented here indicate that pol $\alpha$ obtains fidelity during the polymerization of purine dNTPs using a pair of cleverly designed orthogonal screens. While we have restricted our discussion to purine dNTPs, unpublished studies indicate that pol $\alpha$ uses similar strategies during polymerization of pyrimidine dNTPs (Unpublished data, M. Loi, G. Timblin, and R. Kuchta). Ultimately, a detailed understanding of the requirements for accurate and efficient polymerization of both purine and pyrimidine dNTPs by pol $\alpha$ should allow the generation of novel base-pairs that pol $\alpha$ replicates with high efficiency and fidelity.

\section{References}

1. Roberts, JD.; Kunkel, TA. DNA Replication in Eukaryotic Cells: Concepts, Enzymes and Systems. Depamphilis, M., editor. Cold Spring Harbor Laboratory Press; Cold Spring Harbor, NY: 1996. p. 217-47.

2. Drake JW. A constant rate of spontaneous mutation in DNA-based microbes. Proc Natl Acad Sci USA 1991;88:7160-164. [PubMed: 1831267]

3. Kunkel TA, Bebenek K. Recent studies of the fidelity of DNA synthesis. Biochim Biophys Acta 1988;951:1-5. [PubMed: 2847793]

4. Watson JDCCFH. Molecular Structure of Nucleoic Acids. Nature 1953;171:737-38. [PubMed: 13054692]

5. Watson JD, Crick FHC. Genetical Implications of the Structure of Deoxyribonucleic Acid. Nature 1953;171:964-67. [PubMed: 13063483]

6. Moore CL, Zivkovic A, Engels JW, Kuchta RD. Human DNA primase uses Watson-Crick hydrogen bonds to distinguish between correct and incorrect nucleoside triphosphates. Biochemistry 2004;43:12367-2374. [PubMed: 15379576]

7. Ramirez-Aguilar KA, Moore CL, Kuchta RD. Herpes simplex virus 1 primase employs watson-crick hydrogen bonding to identify cognate nucleoside triphosphates. Biochemistry 2005;44:15585-5593. [PubMed: 16300408]

8. Moran S, Ren RX, Kool ET. A thymidine triphosphate shape analog lacking Watson-Crick pairing ability is replicated with high sequence selectivity. Proc Natl Acad Sci USA 1997;94:10506-0511. [PubMed: 9380669]

9. Morales JC, Kool ET. Efficient replication between non-hydrogen-bonded nucleoside shape analogs. Nat Struct Biol 1998;5:950-54. [PubMed: 9808038]

10. Morales JC, Kool ET. Varied Molecular Interactions at the Active Sites of Several DNA Polymerases: Nonpolar Nucleoside Isosteres as Probes. J Am Chem Soc 2000;122:1001-007.

11. Kincaid K, Beckman J, Zivkovic A, Halcomb RL, Engels JW, Kuchta RD. Exploration of factors driving incorporation of unnatural dNTPS into DNA by Klenow fragment (DNA polymerase I) and DNA polymerase alpha. Nucleic Acids Res 2005;33:2620-628. [PubMed: 15879351]

12. Chiaramonte M, Moore CL, Kincaid K, Kuchta RD. Facile polymerization of dNTPs bearing unnatural base analogues by DNA polymerase alpha and Klenow fragment (DNA polymerase I). Biochemistry 2003;42:10472-0481. [PubMed: 12950174]

13. Zerbe LK, Goodman MF, Efrati E, Kuchta RD. Abasic template lesions are strong chain terminators for DNA primase but not for DNA polymerase alpha during the synthesis of new DNA strands. Biochemistry 1999;38:12908-2914. [PubMed: 10504262]

14. Wenzel T, Seela F. Synthesis of 6-substituted 1-deazapurine 2'-deoxyribonucleosides. Helvetica Chimica Acta 1996;79:169-78.

15. Seela F, Rosemeyer H, Fischer S. Synthesis of 3-Deaza-2-deoxyadenosine and 3-Deaza-2,3dideoxyadenosine: Glycosylation of the 4-Chloroimidazo[4,5-c]pyridinyl Anion. Helvetica Chimica Acta 1990;73:1602-611. 
16. Morales JC, Kool ET. Minor Groove Interactions between Polymerase and DNA: More Essential to Replication than Watson-Crick Hydrogen Bonds? J Am Chem Soc 1999;121:2323-324.

17. Cosstick R, Li X, Tuli DK, Williams DM, Connolly BA, Newman PC. Molecular recognition in the minor groove of the DNA helix. Studies on the synthesis of oligonucleotides and polynucleotides containing 3-deaza-2'-deoxyadenosine Interaction of the oligonucleotides with the restriction endonuclease EcoRV. Nucleic Acids Res 1990;18:4771-778. [PubMed: 2395641]

18. Washington MT, Wolfe WT, Spratt TE, Prakash L, Prakash S. Yeast DNA polymerase eta makes functional contacts with the DNA minor groove only at the incoming nucleoside triphosphates. Proc Natl Acad Sci USA 2003;100:5113-118. [PubMed: 12692307]

19. Ludwig J. A new route to nucleoside 5'-triphosphates. Acta Biochim Biophys Acad Sci Hung 1981;16:131-33. [PubMed: 7347985]

20. Kazimierczuk Z, Cottam HB, Revankar GR, Robins RK. Synthesis of 2'-deoxytubercidin, 2'deoxyadenosine, and related 2'-deoxynucleosides via a novel direct stereospecific sodium salt glycosylation procedure. J Am Chem Soc 1984;106:6379-382.

21. Antonini I, Cristalli G, Franchetti P, Grifantini M, Martelli S, Petrelli F. Deaza analogues of adenosine as inhibitors of blood platelet aggregation. J Pharm Sci 1984;73:366-69. [PubMed: 6716245]

22. Middleton RW, Wibberley DG. Synthesis of Imnidazo[4,5-b]- and [4,5-c]pyridines. J Heterocyclic Chem 1980;17:1757-760.

23. Hocková D, Hocek M, Dvoøáková H, Votruba I. Synthesis and cytostatic activity of nucleosides and acyclic nucleoside analogues derived from 6-(trifluoromethyl)purines. Tetrahedron 1999;55:11109_ 1118.

24. Hocek M, Dvoøáková H. An Efficient Synthesis of 2-Substituted 6-Methylpurine Bases and Nucleosides by Fe- or Pd-Catalyzed Cross-Coupling Reactions of 2,6-Dichloropurines. J Org Chem 2003;68:5773-776. [PubMed: 12839482]

25. Votruba I, Holý A, Dvoøáková H, Günter J, Hocková D, Høebabecký H, Cihláø T, Msojídková M. Synthesis of 2-Deoxy-b-D-ribonucleosides and 2,3-Dideoxy-b-D-pentofuranosides on Immobilized Bacterial Cells. Collect Czech Chem Commun 1994;59:2303-330.

26. Hassan AEA, Abou-Elkair RAI, Montgomery JA, Secrist JA III. Convenient syntheses of 6methylpurine and related nucleosides. Nucleosides Nucleotides Nucleic Acids 2000;19:1123-134. [PubMed: 10999252]

27. Hocek M, Holý A. Perfluoroalkylation of 6-Iodopurines by Trimethyl(perfluoroalkyl)silanes. Synthesis of 6-(Perfluoroalkyl)purine Bases, Nucleosides and Acyclic Nucleotide Analogues. Collect Czech Chem Commun 1999;64:229-41.

28. Maniatis, T.; Fritsch, EF.; Sambrook, J. Molecular Cloning. Cold Spring Harbor Laboratory; Cold Spring Harbor, NY: 1982.

29. Kuchta RD, Mizrahi V, Benkovic PA, Johnson KA, Benkovic SJ. Kinetic mechanism of DNA polymerase I (Klenow). Biochemistry 1987;26:8410-417. [PubMed: 3327522]

30. Goodman MF, Creighton S, Bloom LB, Petruska J. Biochemical basis of DNA replication fidelity. Crit Rev Biochem Mol Biol 1993;28:83-126. [PubMed: 8485987]

31. Leo AJ. Hydrophobic parameter: measurement and calculation. Methods Enzymol 1991;202:54491. [PubMed: 1784188]

32. Franklin MC, Wang J, Steitz TA. Structure of the replicating complex of a pol alpha family DNA polymerase. Cell 2001;105:657-67. [PubMed: 11389835]

33. Liu S, Knafles JD, Chang JS, Waszak GA, Baldwin ET, Deibel MR Jr, Thomsen DR, Homa FL, Wells PA, Tory MC, Poorman RA, Gao H, Qiu X, Seddon AP. Crystal structure of the herpes simplex 1 virus DNA polymerase. J Biol Chem. 2006In Press

34. Wang TS, Wong SW, Korn D. Human DNA polymerase alpha: predicted functional domains and relationships with viral DNA polymerases. Faseb J 1989;3:14-1. [PubMed: 2642867]

35. Wang J, Sattar AK, Wang CC, Karam JD, Konigsberg WH, Steitz TA. Crystal structure of a pol alpha family replication DNA polymerase from bacteriophage RB69. Cell 1997;89:1087-099. [PubMed: 9215631]

36. Mercozzi S, West APJ, Dougherty DA. Cation- interactions in aromatics of biological and medicinal interest: Electrostatic potential surfaces as a useful qualitative guide. Proc Natl Acad Sci USA 1996;93:10566-0571. [PubMed: 8855218] 
37. Yang G, Wang J, Konigsberg W. Base Selectivity is Impaired by Mutants that Perturb Hydrogen Bonding Networks in the RB69 DNA Polymerase Active Site. Biochemistry 2005;44:3338-346. [PubMed: 15736944]

38. Mendelman LV, Petruska J, Goodman MF. Base mispair extension kinetics. Comparison of DNA polymerase alpha and reverse transcriptase. J Biol Chem 1990;265:2338-346. [PubMed: 1688852]

39. Perrino FW, Loeb LA. Differential extension of 3 ' mispairs is a major contribution to the high fidelity of calf thymus DNA polymerase-alpha. J Biol Chem 1989;264:2898-905. [PubMed: 2521632]

40. Kool ET, Morales JC, Guckian KM. Mimicking the Structure and Function of DNA: Insights into DNA Stability and Replication. Angew Chem Int Ed Engl 2000;39:990-1009. [PubMed: 10760910]

41. Kool ET. Active site tightness and substrate fit in DNA replication. Annu Rev Biochem 2002;71:19119. [PubMed: 12045095]

42. Sintim HO, Kool ET. Remarkable sensitivity to DNA base shape in the DNA polymerase active site. Angew Chem Int Ed Engl 2006;45:1974-979. [PubMed: 16506248]

43. Ogawa AK, Wu Y, McMinn DL, Liu J, Schultz PG, Romesberg FE. Efforts toward the Expansion of the Genetic Alphabet: Information Storage and Replication with Unnatural Hydrophobic Base Pairs. J Am Chem Soc 2000;122:3274-287.

44. Berger M, Wu Y, Ogawa AK, McMinn DL, Schultz PG, Romesberg FE. Universal bases for hybridization, replication and chain termination. Nucleic Acids Res 2000;28:2911-914. [PubMed: 10908353]

45. Wu Y, Ogawa AK, Berger M, McMinn DL, Schultz PG, Romeberg FE. Efforts toward Expansion of the Genetic Alphabet: Optimization of Interbase Hydrophobic Interactions. J Am Chem Soc 2000;122:7621-632.

46. Ogawa AK, Wu Y, Berger M, Schultz PG, Romeberg FE. Rational Design of an Unnatural Base Pair with Increased Kinetic Selectivity. J Am Chem Soc 2000;122:8803-804.

47. Hendrickson CL, Devine KG, Benner SA. Probing minor groove recognition contacts by DNA polymerases and reverse transcriptases using 3-deaza-2'-deoxyadenosine. Nucleic Acids Res 2004;32:2241-250. [PubMed: 15107492] 
a:<smiles>Cn1cnc2ccccc21</smiles>

Benzimidazole

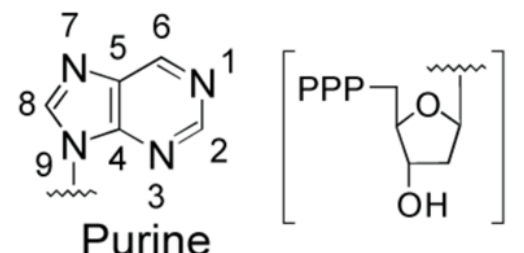

Purine

b:<smiles>CC(C)n1cnc2ccccc21</smiles><smiles>CC(C)n1cnc2cccnc21</smiles><smiles>CC(C)n1cnc2cnccc21</smiles><smiles>Cn1cnc2cncnc21</smiles><smiles>CC(C)n1cnc2c(N)cccc21</smiles><smiles>Cc1cccc2c1ncn2C(C)C(F)(F)F</smiles><smiles>CC(C)n1cnc2c(N)ccnc21</smiles><smiles>CC(C)(C(=O)O)n1cnc2c(N)nccc21</smiles><smiles>COC(=O)C(C)n1cnc2c(C)ccnc21</smiles>

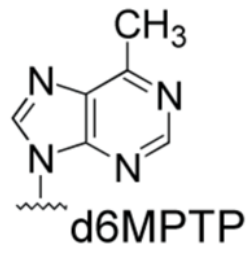<smiles>CC(C)(n1cnc2c(C(F)(F)F)cccc21)C(F)(F)F</smiles><smiles></smiles><smiles>CC(C)(n1cnc2c(N)ncnc21)[Ge](F)(F)F</smiles>

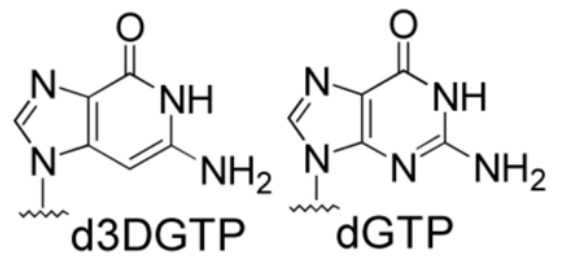

Figure 1.

The structures, names, and numbering schemes of the dNTPs discussed. a: Generic structure of benzimidazole and purine 2'-deoxyribofuranosyl-5'-triphosphates, including numbering schemes for the two aromatic systems. b: Analog and natural dNTPs discussed. 


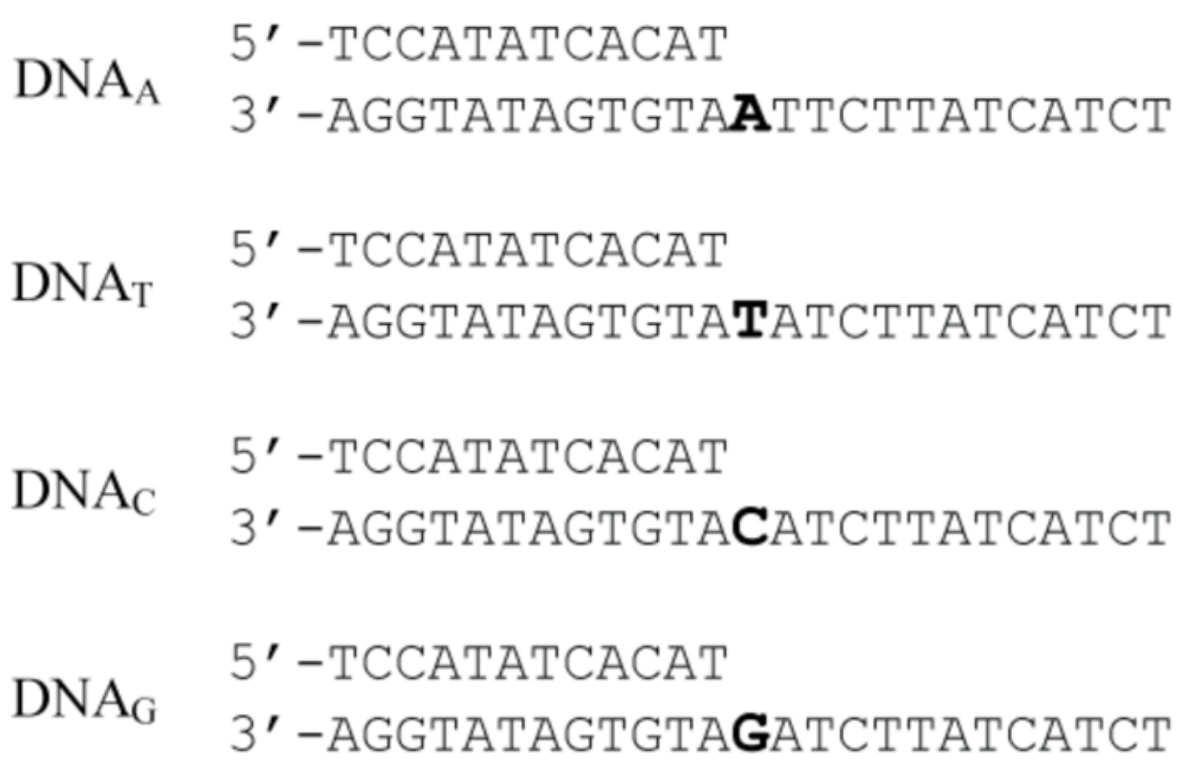

Figure 2.

The four primer-template sequences used in this study to determine incorporation rates by human pol $\alpha$. The template base immediately opposite the incoming nucleotide is in bold. 


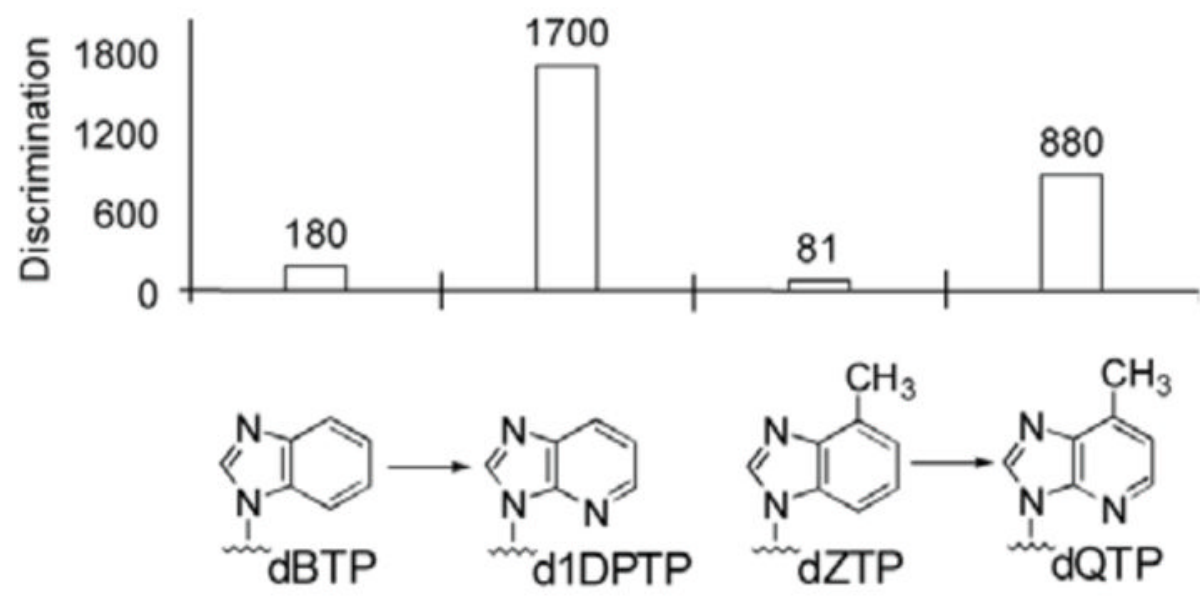

Figure 3.

Effect of adding N-3 to the low fidelity bases benzimidazole (dBTP) and 4methylbenzimidazole (dZTP) to generate 1-deazapurine (d1DPTP) and 1-deaza-6methylpurine (dQTP). The open bars in the graph are the average value by which pol $\alpha$ discriminates against polymerization of each analogue opposite $\mathrm{A}, \mathrm{C}, \mathrm{T}$, and $\mathrm{G}$ relative to polymerization of a correct dNTP. 

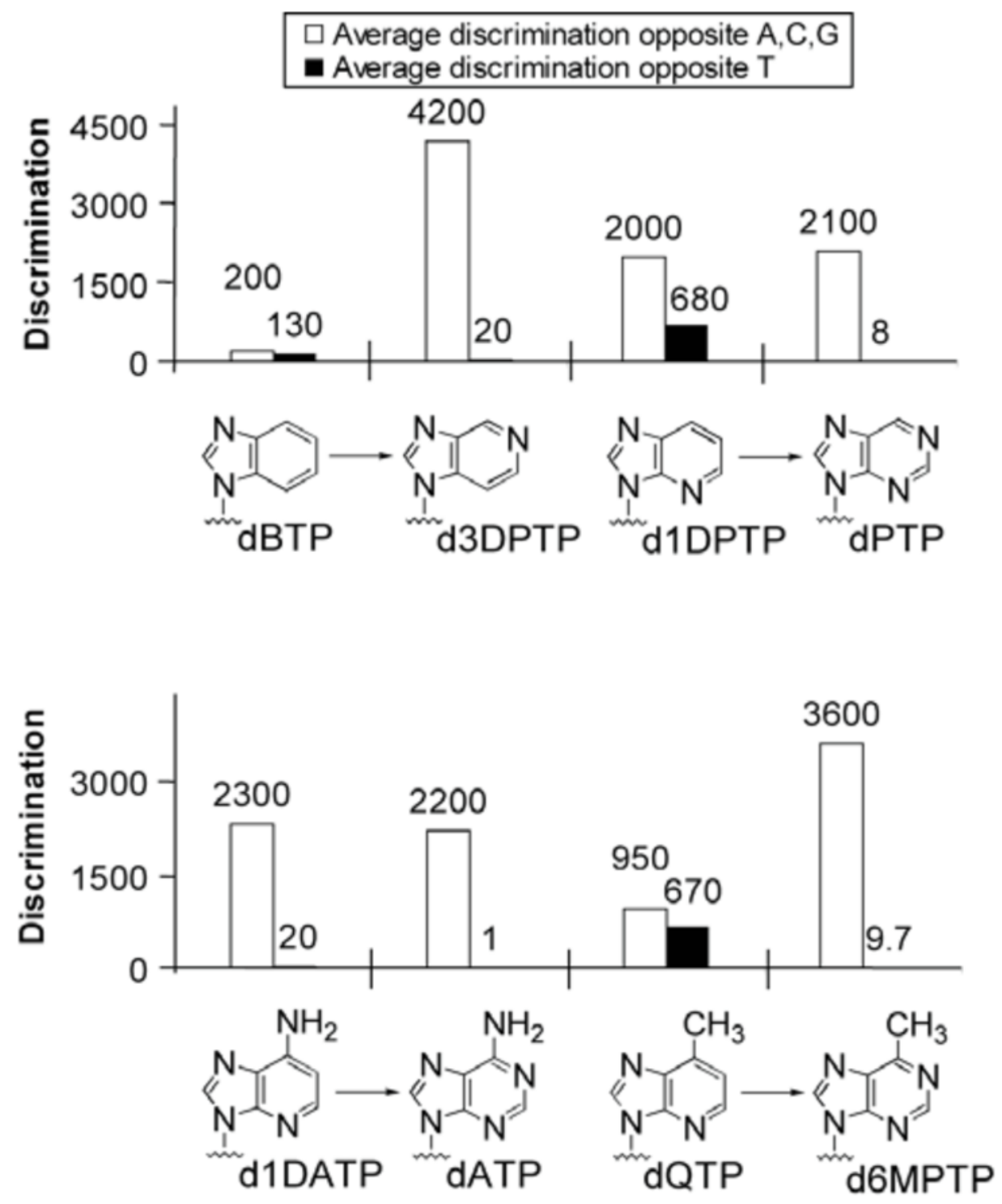

Figure 4.

Adding N-1 to benzimidazole (dBTP) or 1-deaza-6-methylpurine (dQTP) increases polymerization opposite $\mathrm{T}$ and decreases polymerization opposite $\mathrm{A}, \mathrm{C}$, and $\mathrm{G}$. The open bars in the graph are the average value by which pol $\alpha$ discriminates against polymerization of each analogue opposite $\mathrm{A}, \mathrm{C}$, and $\mathrm{G}$ relative to polymerization of a correct dNTP, while the black bars show how much slower pol $\alpha$ polymerizes each analogue opposite $\mathrm{T}$ as compared to dATP. 


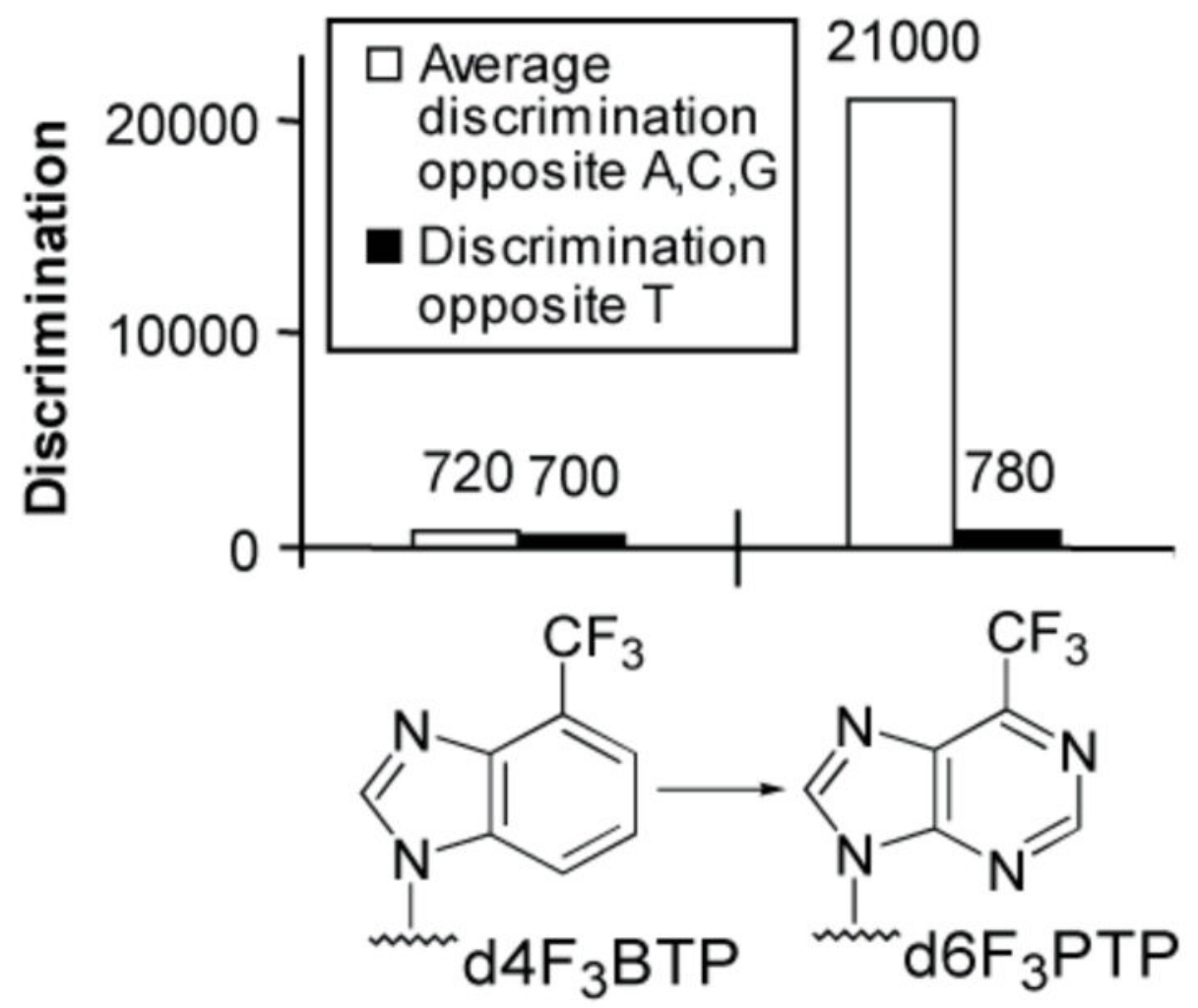

Figure 5.

Generating $\mathrm{d}_{6} \mathrm{~F}_{3} \mathrm{PTP}$ by adding $\mathrm{N}-1$ and $\mathrm{N}-3$ to $\mathrm{d} 4 \mathrm{~F}_{3} \mathrm{BTP}$ decreases polymerization opposite $\mathrm{A}, \mathrm{C}$, and $\mathrm{G}$ while maintaining polymerization opposite $\mathrm{T}$. The open bars in the graph are the average value by which pol $\alpha$ discriminates against polymerization of each analogue opposite $\mathrm{A}, \mathrm{C}$, and $\mathrm{G}$ relative to polymerization of a correct dNTP, while the black bars show how much slower pol $\alpha$ polymerizes each analogue opposite $\mathrm{T}$ as compared to dATP. 

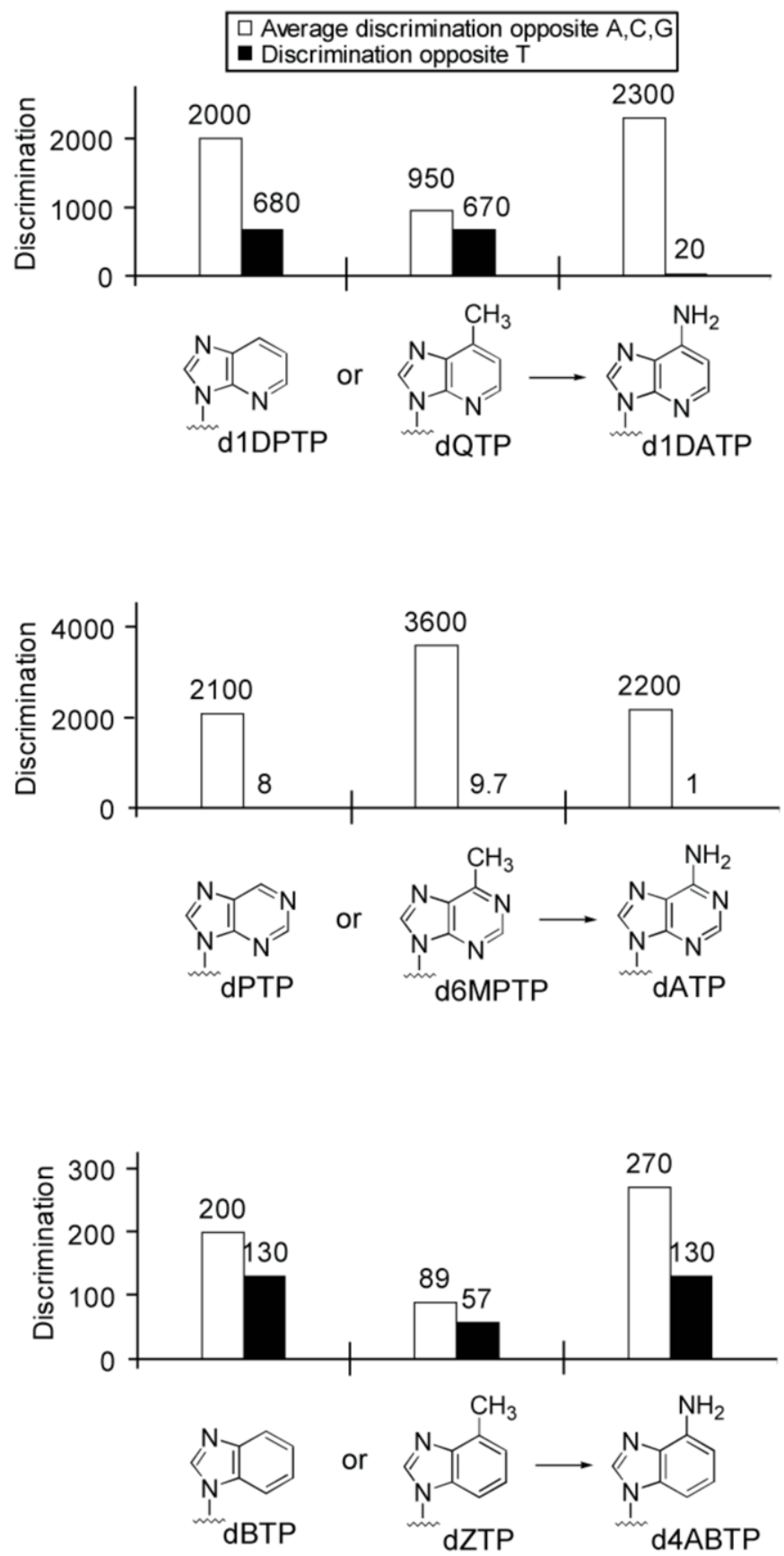

Figure 6.

Effect of adding the equivalent of adenine's exocyclic amine at C-6 (N-6). The open bars in the graph are the average value by which pol $\alpha$ discriminates against polymerization of each analogue opposite $\mathrm{A}, \mathrm{C}$, and $\mathrm{G}$ relative to polymerization of a correct $\mathrm{dNTP}$, while the black bars show how much slower pol $\alpha$ polymerizes each analogue opposite $\mathrm{T}$ as compared to dATP. 


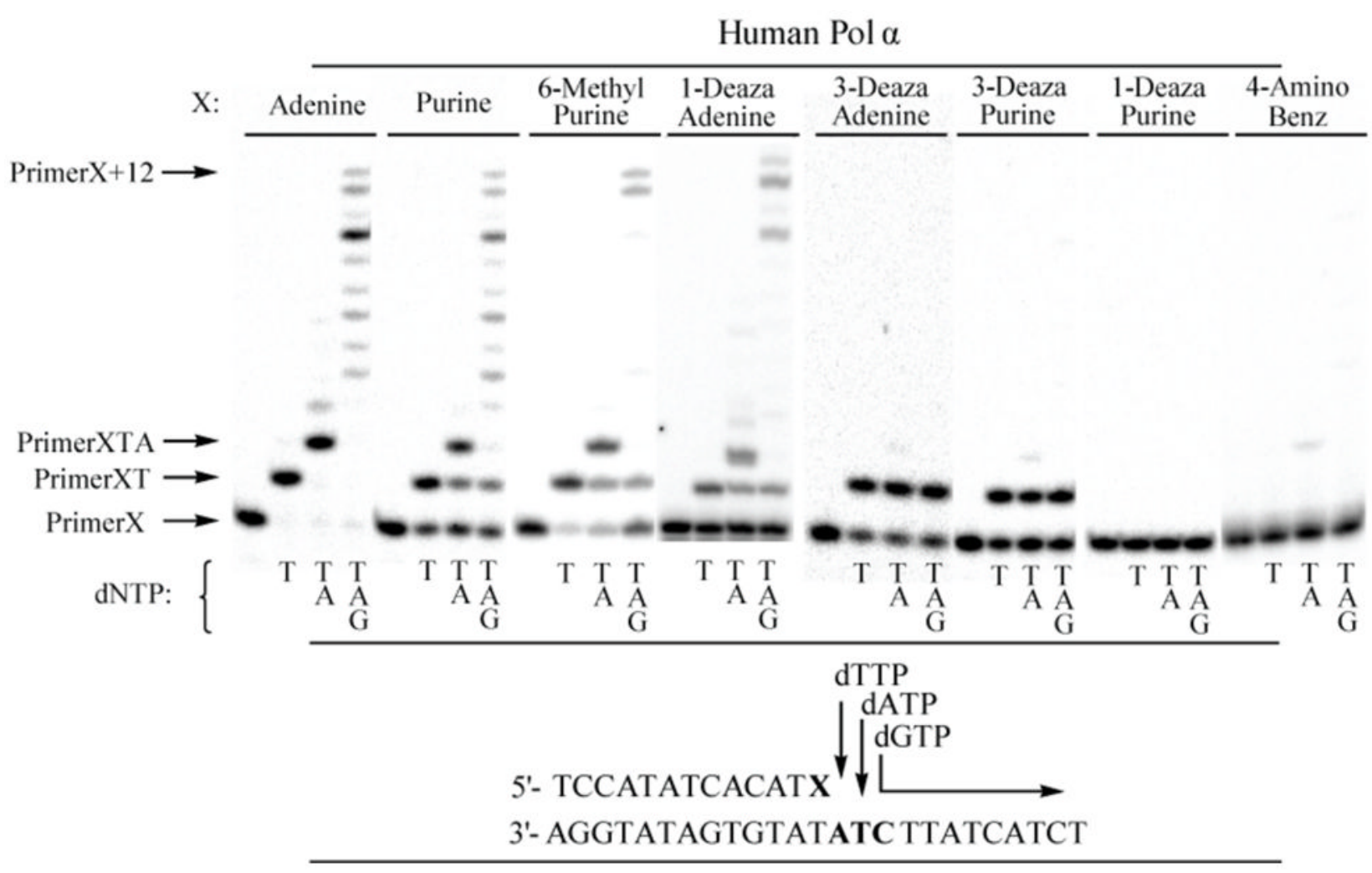

Figure 7.

Read-through comparison of the analogues by human pol $\alpha$. Assays contained $1 \mathrm{nM}$ PrimerXtemplate (where $\mathrm{X}$ represents the analogue at the primer 3 '-terminus), $0.5 \mathrm{nM}$ pol $\alpha$, and 25 $\mu \mathrm{M}$ of the noted dNTPs. 


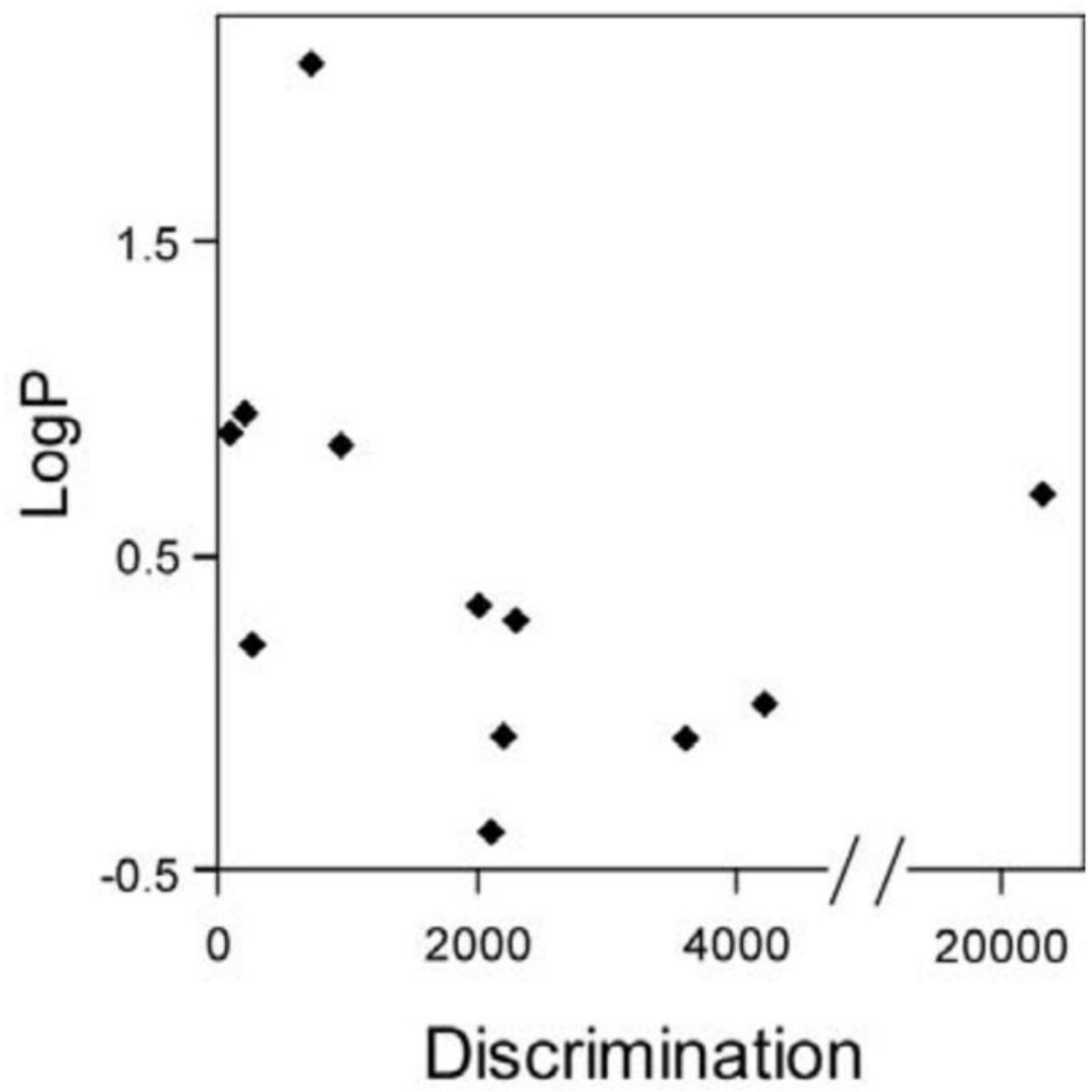

Figure 8.

Plot of base hydrophobicity ( $\log$ P) versus fidelity of base-dNTP opposite templates A, C, and $\mathrm{G}$ (The average of the three discrimination numbers, taken from Table 2). 


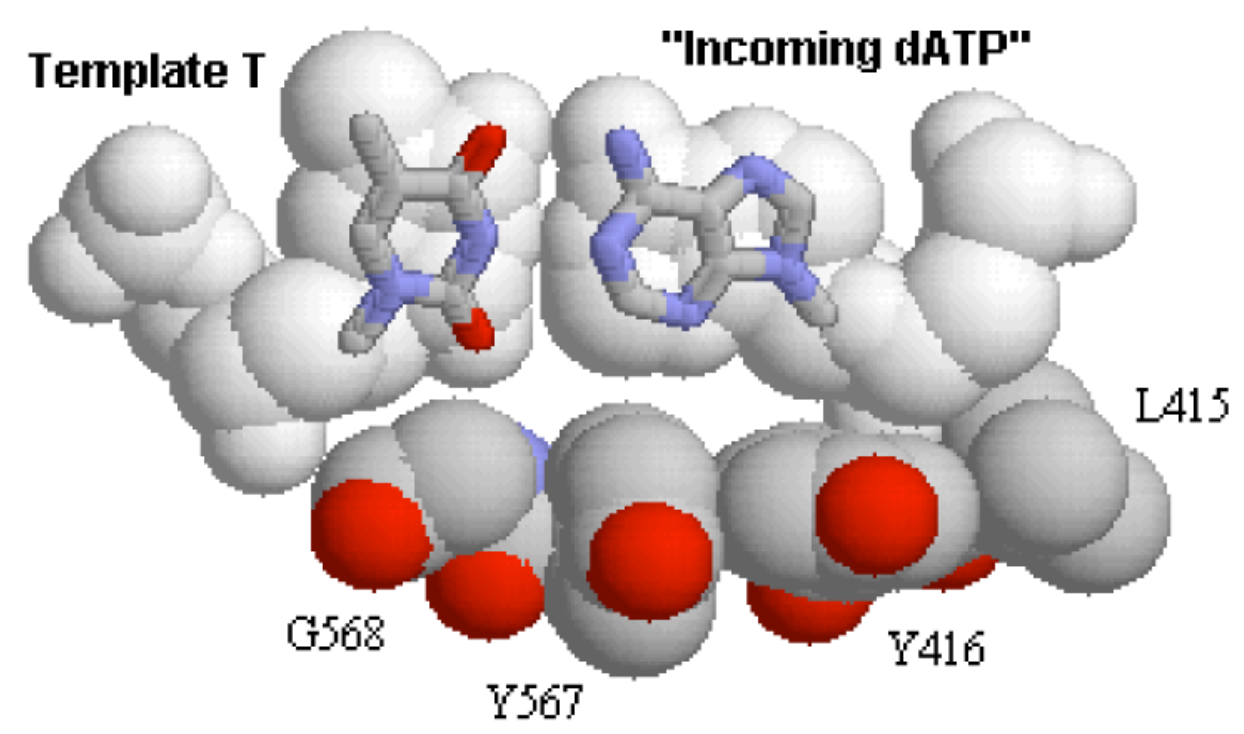

Figure 9.

Shown is a representation of an incoming dATP and a template T inside the active site of RB69 (adapted from the data in PDB 1IG9). We replaced the dTTP:A base-pair with a dATP:T basepair while maintaining the location of the sugar-phosphates of each nucleotide. Only selected residues are shown for simplicity. 
Table 1

Kinetic Parameters for Correct Incorporation of Natural dNTPs by Human Pol $\alpha^{a}$

\begin{tabular}{ccccc}
\hline dNTP & DNA $_{\mathbf{N}}$ & $\mathbf{V}_{\mathbf{M A X}}$ & $\mathbf{K}_{\mathbf{M}}$ & $\mathbf{V}_{\mathbf{M A X}} / \mathbf{K}_{\mathbf{M}}$ \\
\hline dTTP & & $3.6(1.4)$ & $2.7(1.4)$ & 1.3 \\
dATP & DNA $_{\mathrm{A}}$ & $10(1.4)$ & $5.9(2.5)$ & 1.7 \\
dGTP & DNA $_{\mathrm{T}}$ & $8.2(3.1)$ & $1.4(0.5)$ & 5.9 \\
dCTP & DNA $_{\mathrm{C}}$ & $5.5(1.5)$ & $6.6(2.0)$ & 0.8 \\
\hline
\end{tabular}

${ }^{a}$ Assays were performed and analyzed as described in Experimental Procedures. SD $=$ Standard Deviation. The units for VMAX and $\mathrm{K}_{\mathrm{M}}$ are $\%$ of primer elongated $\min ^{-1}$ and $\mu \mathrm{M}^{-1}$, respectively. The units for $\mathrm{V}_{\mathrm{MAX}} / \mathrm{KM}_{\mathrm{M}}$ are $\%$ elongated $\mu \mathrm{M}^{-1} \min ^{-1}$. 


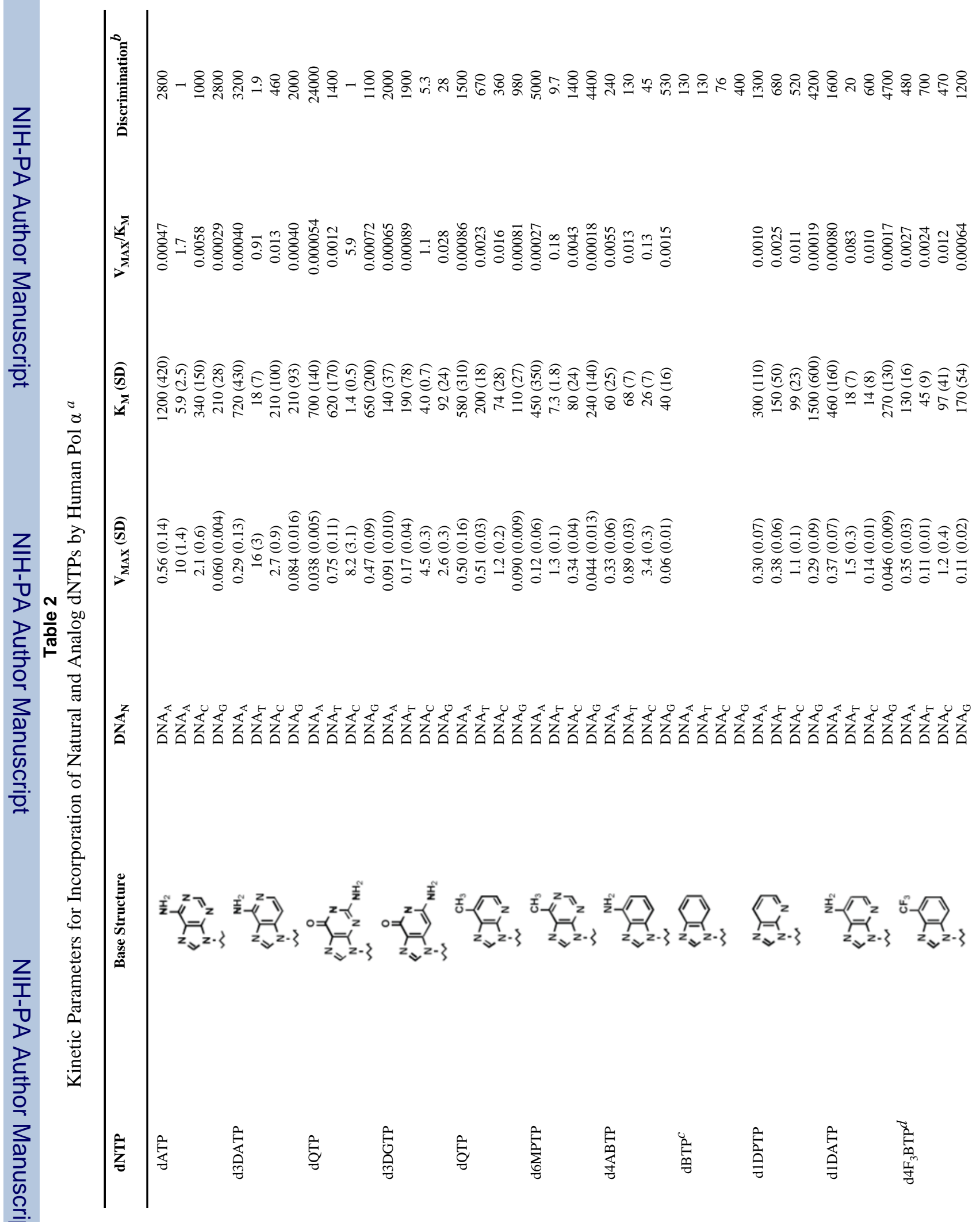


Beckman et al.

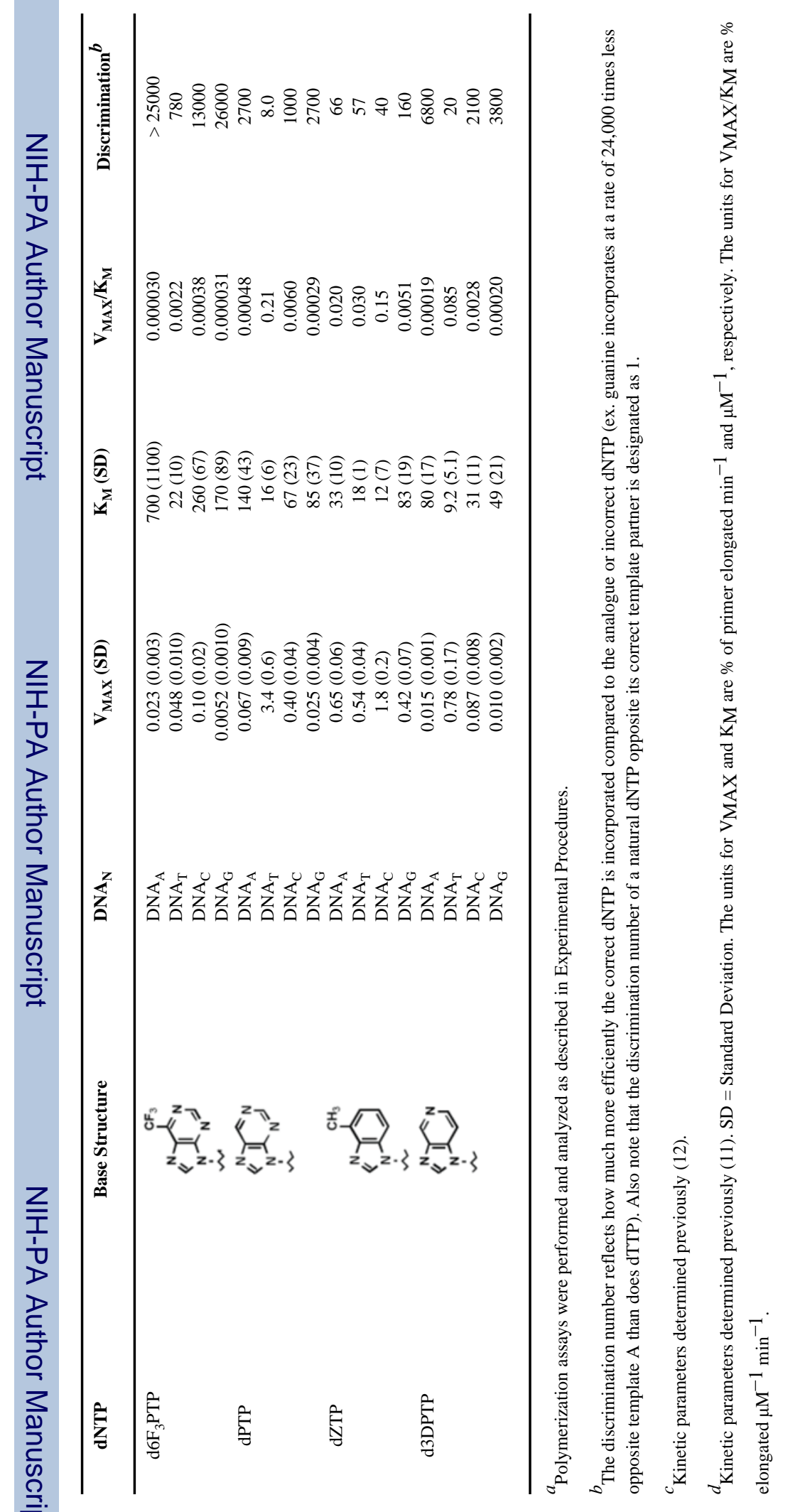


Table 3

Next Correct dNTP Insertion by Human Pol $\alpha$ (dTTP insertion following analogue X) ${ }^{a}$

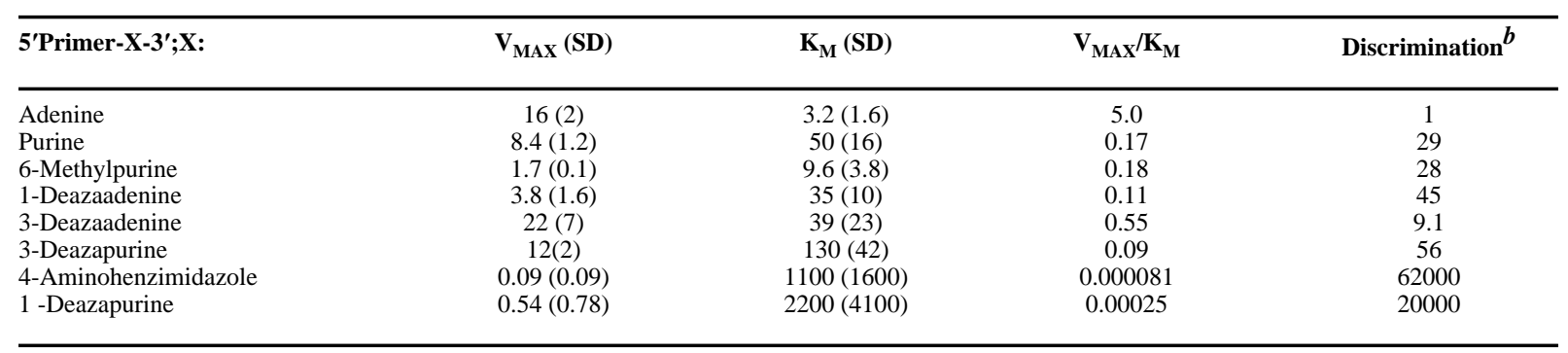

\footnotetext{
${ }^{a}$ Polymerization read-through assays were performed as described in Experimental Procedures. Kinetic parameters for dTTP polymerization were determined when either A or the noted analogue was present at the primer terminus.

$b_{\text {The discrimination is }} \mathrm{V}_{\mathrm{MAX}} / \mathrm{K}_{\mathrm{M}}$ for dTTP polymerization when $\mathrm{A}$ is at the primer terminus divided by $\mathrm{V}_{\mathrm{MAX}} / \mathrm{K}_{\mathrm{M}}$ when an analogue $(\mathrm{X})$ is at the primer terminus. $\mathrm{SD}=$ Standard Deviation. The units for $\mathrm{V}_{\mathrm{MAX}} / \mathrm{K}_{\mathrm{M}}$ are $\%$ elongated $\mu \mathrm{M}^{-1} \min ^{-1}$
} 
Table 4

Insertion of Second Correct dNTP by Human Pol $\alpha$ (dATP insertion after T) ${ }^{a}$

\begin{tabular}{|c|c|c|c|c|}
\hline 5'-Primer-X-T-3';X: & $\mathbf{V}_{\text {MAX }}(S D)$ & $\mathbf{K}_{\mathbf{M}}(\mathbf{S D})$ & $\mathbf{V}_{\text {MAX }} / \mathbf{K}_{\mathbf{M}}$ & Discrimination $b$ \\
\hline Adenine & $30(3)$ & $4.5(2.2)$ & 6.7 & 1 \\
\hline Purine & $16(2)$ & $6.1(2.7)$ & 2.6 & 3 \\
\hline 6-Methylpurine & $6.6(0.6)$ & $5.9(1.5)$ & 1.1 & 6 \\
\hline 1-Deazaadenine & $13(2)$ & $10(4)$ & 1.3 & 5 \\
\hline 3-Deazaadenine & $0.17(0.16)$ & $3.4(1.7)$ & 0.050 & 130 \\
\hline 3-Deazapurine & $0.21(0.02)$ & $4.3(1.7)$ & 0.049 & 140 \\
\hline
\end{tabular}

${ }^{a}$ Polymerization read-through assays were performed as described in Experimental Procedures. Kinetic parameters for dATP polymerization opposite a template $\mathrm{T}$ were determined when either $\mathrm{A}$ or the noted analogue was present one nucleotide before the primer terminus.

${ }^{b}$ The discrimination is $\mathrm{V}_{\mathrm{MAX}} / \mathrm{K}_{\mathrm{M}}$ for $\mathrm{dATP}$ polymerization when $\mathrm{X}$ is adenine divided by $\mathrm{V}_{\mathrm{MAX}} / \mathrm{K}_{\mathrm{M}}$ for $\mathrm{dATP}$ polymerization when $\mathrm{X}$ is an analogue. $\mathrm{SD}=$ Standard Deviation. The units for $\mathrm{V}_{\mathrm{MAX}} / \mathrm{K}_{\mathrm{M}}$ are $\%$ elongated $\mu \mathrm{M}^{-1} \min ^{-1}$ 
Table 5

Sequence Alignment of Several Family B Polymerases ${ }^{a}$

\begin{tabular}{lll}
\hline RB69 & & \\
T4 & 553 & MTAQINRKLLINSLYGALG \\
HSV1 & 549 & NTNQLNRKILINSLYGALG \\
Vent & 804 & DKQQAAIKWCNSVYGFTG \\
Pol $\alpha$ (human) & 503 & DYRQRAIKLLANSYYGYMG \\
Pol I (yeast) & 943 & DIRQKALKLTANSMYGCLG \\
& 937 & DIRQQALKLTANSMYGCLG \\
\hline
\end{tabular}

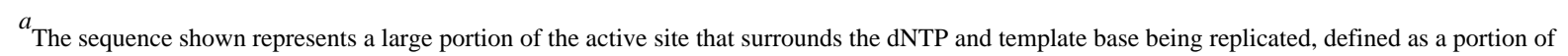
Region III (34). 


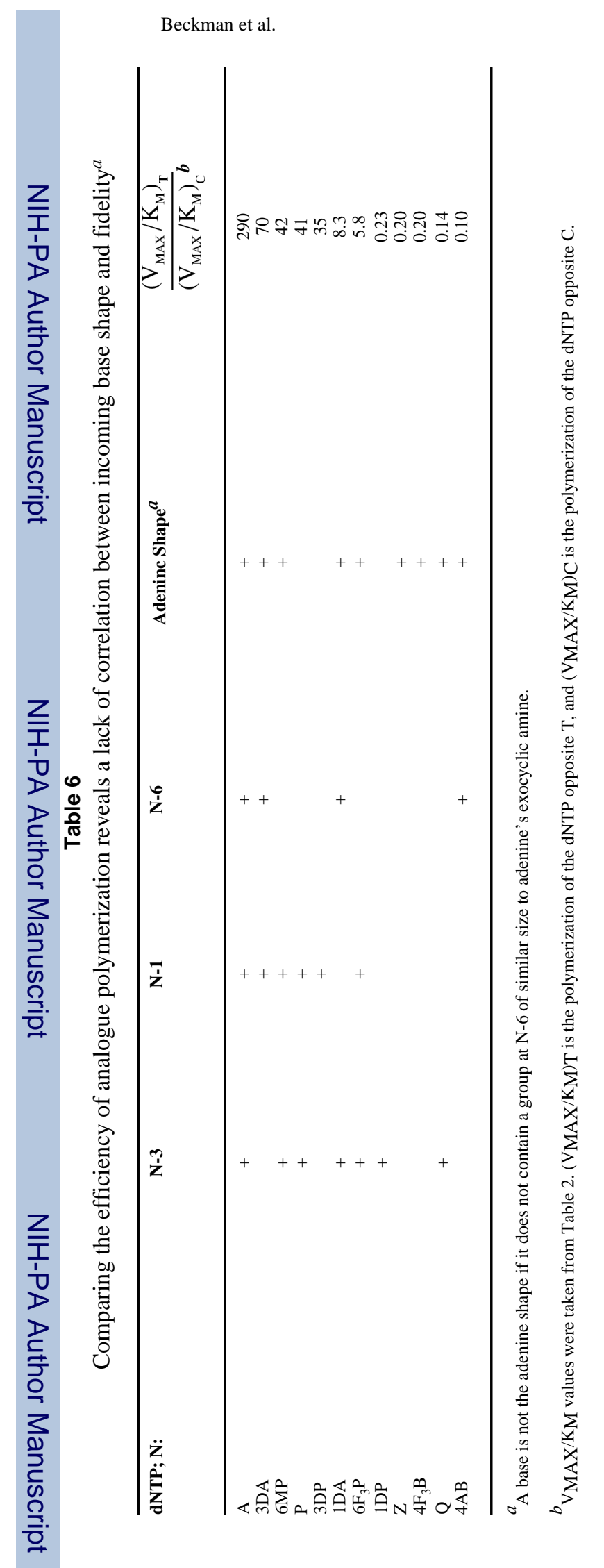

Biochemistry. Author manuscript; available in PMC 2008 August 12. 